\title{
PHOTON: A USER'S MANUAL
}

\author{
Dean Chapman
}

BNL- -40822

DE88 007569

\author{
January 1988
}

\author{
Research Supportod by the \\ OFFICE OF BASIC ENERGY SCIENCES \\ U.S. DEPARTMENT OF ENERGY \\ WASHINGTON, $0 . C$.
}

\section{MATIONAL SYNCHROTRON LIGHT SOURCE}

\section{BROOKHAVEN MATIONAL LABORATOAY} ASSOCIATED UMIVERSITIES, IMC. 


\section{Contents}

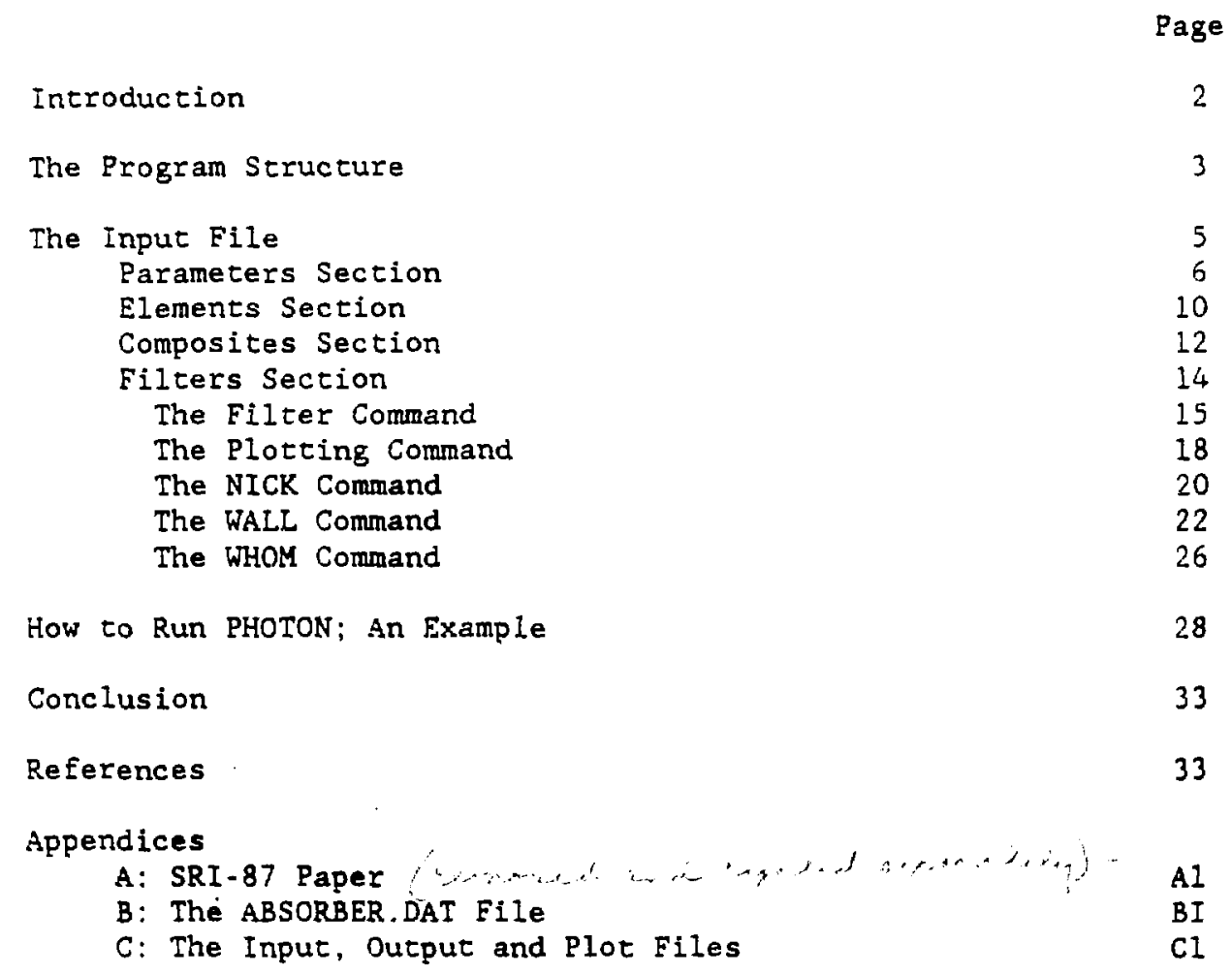




\section{Introduction}

'PHOTON', a FORTRAN program, is an extension of an earlier program 'FILTER' (1) which was used to calculate the spectral effects of filters composed of elements on synchrotron wiggler and bending magnet radiation. The 'FILTER' program also calculated the power deposited in those filters and played a key role in the early design of the $X-27$ Superconducting Wiggler Beamline in terms of power loading in the ring chamber and aperture - mask assemblies. A single electron dipole magnet source is used as the basis for the incident beam spectrum which is calculated in energy and vertical opening angle. Allowance for muleiple poles as in the case of a wiggler device is made by multiplying the dipole source spectrum by the pole number. No consideration is made for electronphoton beam interactions, finite source size or horizontal beam distribution.

Later on in the development of the beamline, it became necessary to calculate the problems associated with the scattered radiation from various elements in the beamline which could be struck by the intense high energy wiggler beam in terms of personnel safety. In order to estimate the level of scatter and what measures should be taken to protect against it, a two pronged approach was taken: 1) to adapt the 'FILTER' progran to calculate the scatter and its attenuation though shielding walls and subsequent dose absorption in materials representative of the human body and 2 ) to experimentally measure the scatter through various filters from existing NSLS $X$-ray bending magnet lines and compare to values calculated using the program(2).

The end result was that we were successfully able to consistently approximate the level of scatter from many materials through many types of filters over a wide dose and energy range. The calculated dose values were higher by factors of 2 to 10 compared to measured values.

A less detailed explanation of the structure and capabilities of the 'PHOTON' program is given in Appendix $A$ which is a reprint of a paper(3) presented at the SRI-87 Conference. 
The program execution is broken into the following parts,

1) Data initialization

2) Input from the terminal requesting the files to be used

a) Input file;

b) Output file;

c) Plotting file.

3) The input file sets parameters such as the ring energy, critical energy, print commands, plot parameters, etc. (this is the PARAMETERS section being read).

4) The incident synchrotron spectrum is calculated in both energy and opening angle based on the parameters.

5) The file containing the spline fitting coefficients for the absorption and cross-section values is read in (the ABSORBER.DAT file).

6) The elements to be used as filters or in composites are read in from the input file (the ELEMENTS section) and the absorption and cross-section values versus energy are calculated.

7) The composites to be defined are read in and the absorption and cross-section values are calculated from the element and mass fractions list.

8) The filter section is then entered, commands are read from the input file in the FILTERS section and appropriate calculations are done based upon the command. If the command is;

a) a Filter command, the transmitted and absorbed power spectra are calculated for this filter; requested - default values of this calculation are printed to the output file.

b) a Plotting command, the appropriate transmitted or scattered spectrum is plotted into the plot file.

c) a WALI command, the inelastically scattered spectrum through a wall of elements-composites is then calculated; requested - default values of this calculation are printed to the output file and a plot of this spectrum is plotted to the plot file. 
d) a WHOM command, the dose absorbed by some medium outside the previous shield wall is calculated and requested default values are printed to the output file.

e) a NICK command, the dose absorbed by some medium in the direct 'filtered' beam is calculated and requested default values are printed to the output file.

The details of how the program works will be covered in the sections which describe the i.lput file, since the program basically follows the structure of this file in its execution. 
The inpuc file name is entered during the execution of the program. This ASCII file is created by the user to define the ring conditions, and beamline conditions for the calculation. An attempt has been made to define the data elements in this file in a logical, self-explanatory way. The file is structured in much the same way the mainline is structured in its execution. Basically, the input file has three parts:

1) the PARAMETERS section,

2) the ELEMENTS and COMPOSITES section,

3) and the FILTERS section.

The structure of each of these sections will now be discussed in detail with a description of what is happening in the mainline program, the allowable input parameters which may be used in each and examples of input parameters. 
This section must be started by the START_PARAMETERS command and terminated by the END_PARAMETERS command. Allowable parameters are 1 isted below with the parameter name to be set (followed in some cases by a numeric value on the next line if required). If the parameter is not specified in the input file the default value at the right will be used and will be printed at the terminal to warn the user that a value has been defaulted to.

Ineumonic Parameter Name Default Value

START_PARAMETERS $<c r>$

Begins the Parameters Section

RING_ENERGY_IN_MEV<cr $>2500.00$

value<cr $>$

or

RING_ENERGY_IN_GEV $\langle c r\rangle \quad 2.50$

value<cr $>$

Storage Ring Energy in $\mathrm{MeV}$ or $\mathrm{GeV}$

MAXIMUM_GAMMA_PSI_IN_RAD<cr $\quad 5.00$

value $<c r>$

Maximum Gamma-Psi from the orbital plane for vertical opening mesh (use this or one of the following two commands for setting this maximum value)

or

MAXIMUM_PSI_IN_MRAD<cr $\quad 1.02$

value<cr $>$

Maximum Opening Angle from the orbital plane, Psi, for the vertical opening mesh in milliradians 
or

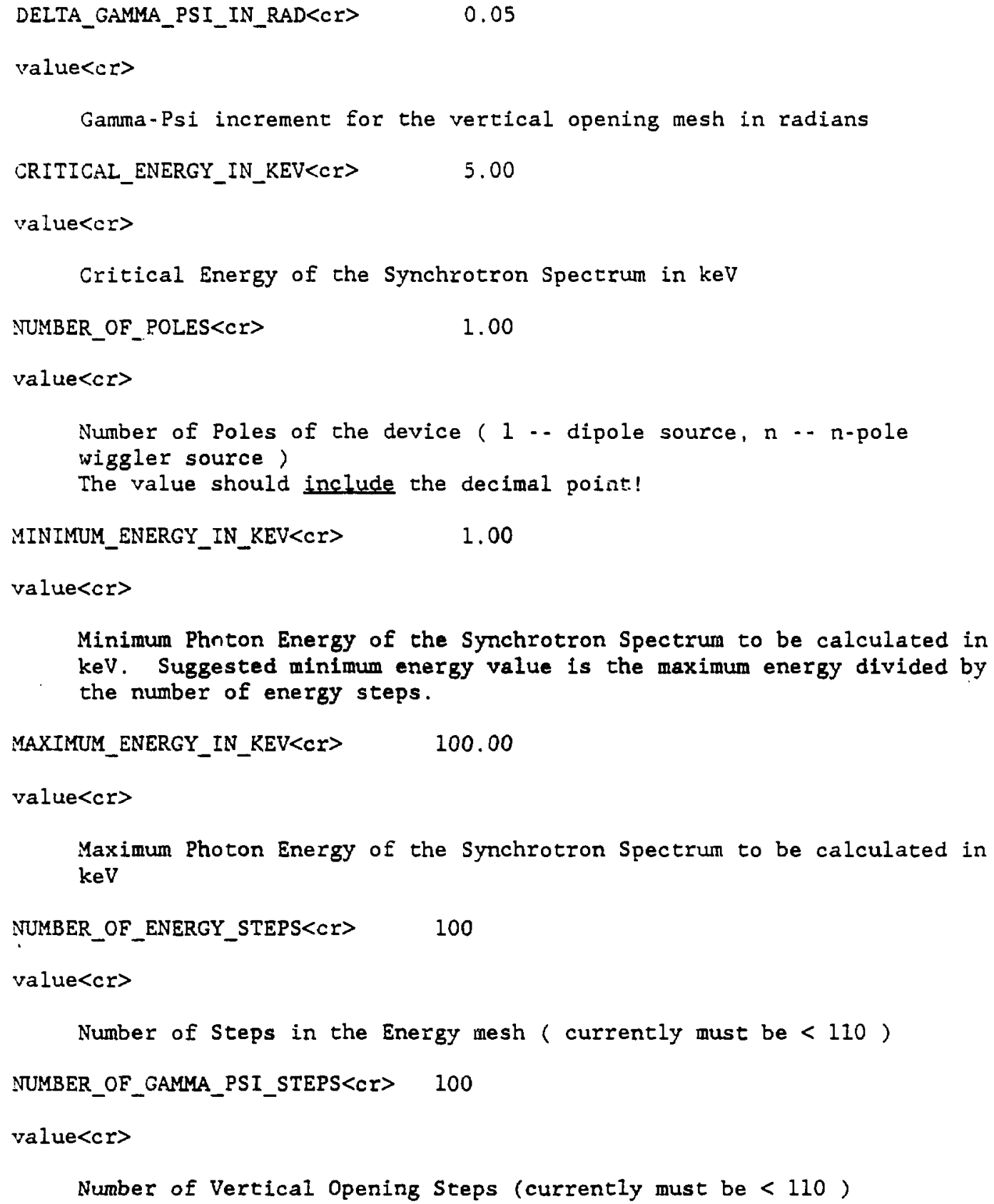




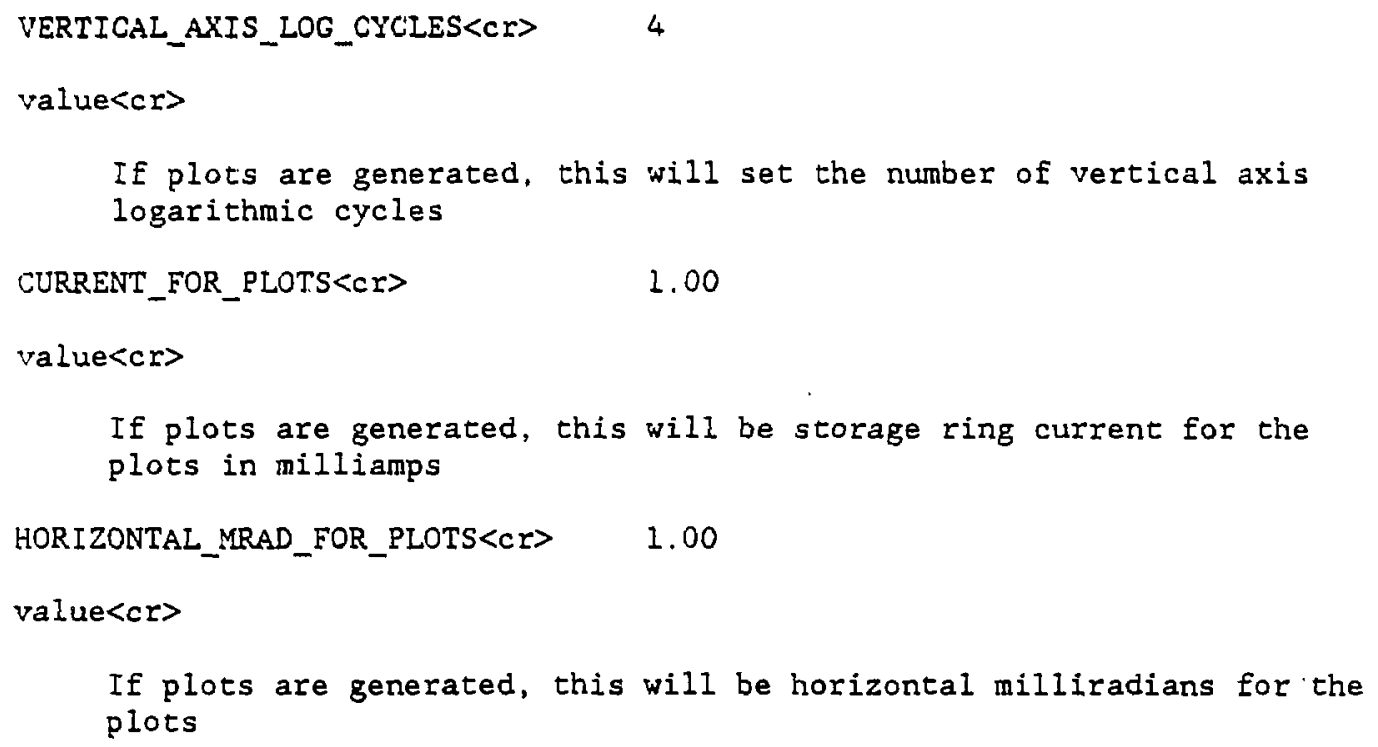


This command forces the printing of the spectrum (photons/ev-sec-mAmphorizontal mrad) transmitted through each filter material using print mesh set by the PRINT_ENERGY_STEPS command

PRINT_ABSORPTION_COEFF $<C r>\quad$ FALSE

This command forces the printing of the absorption coefficients and scattering cross-sections for the elements and materials defined in the elements and composites sections in $\mathrm{cm}^{2} / \mathrm{gram}$ using the PRINT_ENERGY_STEPS mesh

PRINT_TRANS_POWER $<C I>$

FALSE

This command forces the printing of the transmitted power spectrum (watts/eV-vertical mrad-horizontal mrad-mA) transmitted through each filter element using the PRINT_VERTICAL_STEPS and the PRINT_ENERGY_STEPS mesh

PRINT_POWER_SPECTRUMKCr>

FALSE

This command forces the printing of the incident synchrotron power spectrum (watts/eV-vertical mrad-horizontal mrad-mA) using the PRINT_ENERGY_STEPS and the PRINT_VERTICAL_STEPS mesh

PRINT_SCATTERED_SPECTRUM<cr> FALSE

This command forces the printing of the scattered spectrum (photons/ev-sec-ma-horizontal mrad) scattered by each filter element using the PRINT_ENERGY_STEPS mesh

PRINT_ABSORBED_POWER $<c r>\quad$ FALSE

This command forces the printing of the vertical absorbed power spectrum (watts/mA-horizontal mrad-vertical mrad) transmitted through each filter element using the PRINT_VERTICAL_STEPS mesh

SAME_SCALE_FOR_PLOTS $<c r>\quad$ FALSE

This commands forces the plots of the same type to have the same vertical axis range and scale which is set by the first plotting command ( $i e$. the first PLOT command will produce a plot which will be used for all subsequent plots generated by PLOT )

END_PARAMETERS

Must be used to terminate the PARAMETERS section of the input file 
The absorption coefficients and cross-sections for the elements needed later in the progran are calculated based on the elements listed in the input file in the elements section. The absorption coefficients, AMU, EMU, SIGCOH, SIGINC and SIGEN, are defined here using a spline fitting routine with fitting values obtained from a file ABSORBER.DAT. The interpretacion of these values is as follows ( all are in units of $\mathrm{cm}^{2} / \mathrm{gm}$ at an energy $E$ ):

$$
\begin{aligned}
& \text { AMU(E) - the photoelectric absorption coefficient; } \\
& \text { EMU(E) - the part of the photoelectric absorption coefficient which } \\
& \text { results in energy absorption in the material; } \\
& \text { SIGCOH(E) - the total angularly integrated coherent or elastic cross- } \\
& \text { section; } \\
& \text { SIGINC(E) - the total angularly integrated incoherent, inelastic, or } \\
& \text { Compton cross-section; } \\
& \text { SIGEN(E) - the total cross-section for scattering which results in } \\
& \text { energy being deposited in the material. }
\end{aligned}
$$

This section must be started by the START_ELEMENTS command and terminated by the END_ELEMENTS command. Elements currently implemented are listed below with the standard symbol and followed by the 2 of the element and the name written out. Note that the element symbol letters must be upper case for the symbol to be understood. The elements are defined by the ABSORBER. DAT file described in appendix $B$. The addition of an element to the list requires that the ABSORBER.DAT file be updaced with that elements name and appropriate coefficients as described in the appendix.

$\begin{array}{ll}\text { Element } & \text { Z Full Name } \\ \mathrm{H} & 1 \text { Hydrogen } \\ \mathrm{HE} & 2 \text { Helium } \\ \mathrm{BE} & 4 \text { Beryllium } \\ \mathrm{C} & 6 \text { Carbon } \\ \mathrm{N} & 7 \text { Nitrogen } \\ \mathrm{O} & 8 \text { Oxygen } \\ \mathrm{AL} & 13 \text { Aluminum } \\ \mathrm{SI} & 14 \text { Silicon } \\ \mathrm{P} & 15 \text { Phosphoru } \\ \mathrm{AR} & 18 \text { Argon } \\ \mathrm{CA} & 20 \text { Calcium } \\ \mathrm{CR} & 24 \text { Chromium } \\ \mathrm{MN} & 25 \text { Manganese } \\ \mathrm{FE} & 26 \text { Iron }\end{array}$




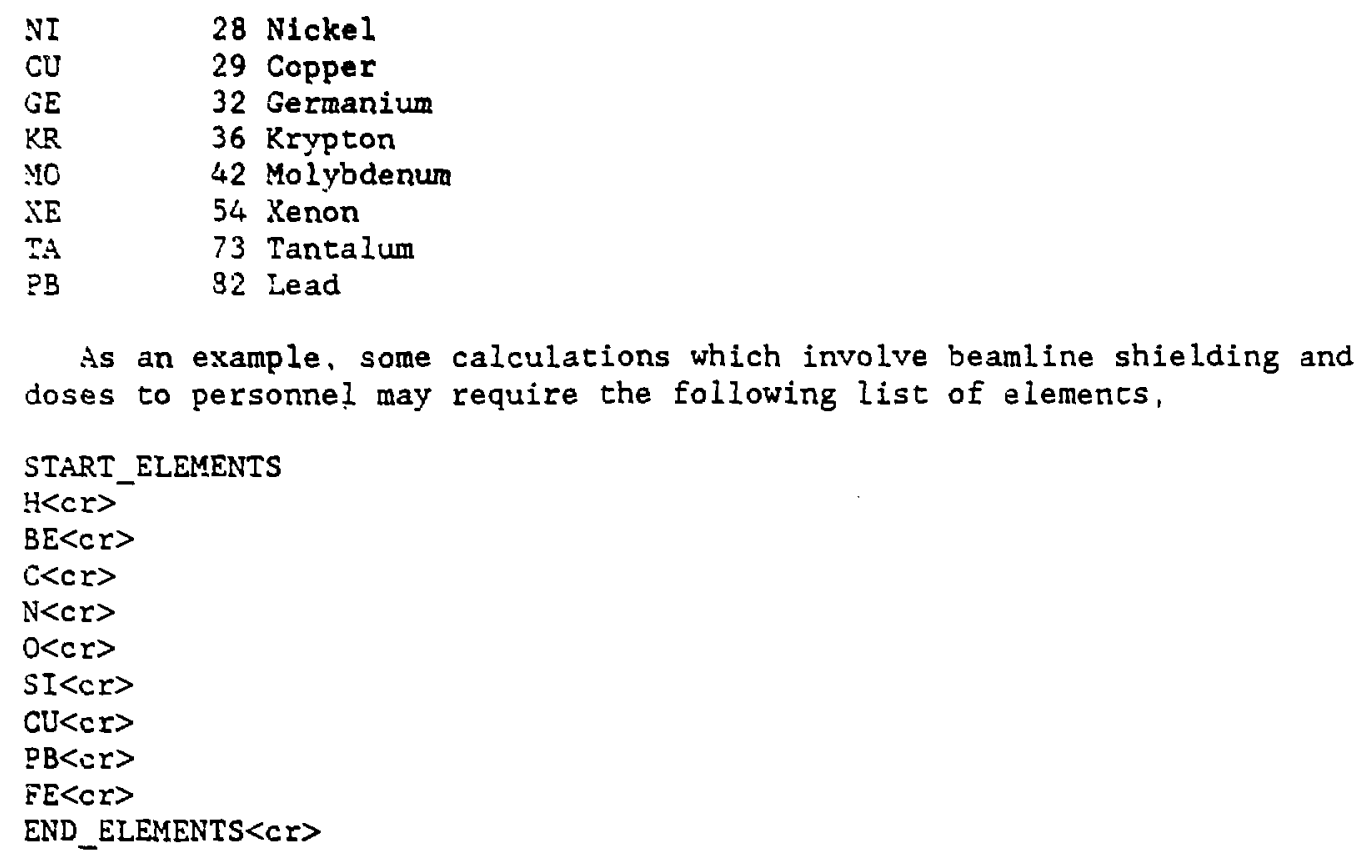


The composites section allows the definition of absorption and crosssection values for materials more complex than the elements defined in the elements section. These values are calculated using the general relation,

$$
\operatorname{SIGMA}(E, \operatorname{COMP})=\sum_{z} \operatorname{SIGMA}(E, Z) * F(Z)
$$

where,

SIGMA(E,COMP) - the absorption or cross-section value in $\mathrm{cm}^{2} / \mathrm{gm}$ at an energy $E$ for the composite;

SIGMA(E,Z) - the absorption or cross-section value in $\mathrm{cm}^{2} / \mathrm{gm}$ at an energy $E$ for an element $Z$ in the composite;

$F(z)$

- the mass fraction of the element $Z$ in the composite

Here the value SIGMA can be any one of the five absorption or crosssections calculated in the program ( ie. AMU, the photoelectric absorprion coefficient; EMU, the energy absorption coefficient; SIGCOH, the elastic scattering cross-section; SIGINC, the inelastic or Compton scattering cross-section; and SIGEN, the energy absorption scattering cross-section)

This section must be started by the START_COMPOSITES command and terminated by the END_COMPOSITES command. I $\bar{f}$ no composites are to be defined in this section, the start - end commands can be skipped altogether. Allowable composites are have names Iimited to five (5) letters and should be restricted to only upper case. Note that no check is made for case in the filter section of the program, so that the case of the name must be consistent between sections. The elements used to define the composites must have already been defined in the elements section before they are used in this section. The mass fraction of each element in the composite must be computed to define the composite. In the composites section the following sequence is necessary in order to define each material:

1) Name of the Composite ( 5 char. or less);

2) Name of an element followed on the next line by the mass fraction of the element;

3) Step 2 is repeated until all elements and their mass fractions have been included;

4) Composite terminated by the END_COMPOSITE name command. 
To more fully emphasize this point we will consider the case of the composite material, water:

Composite WATER, $\mathrm{H}_{2} \mathrm{O}$

Atomic Weight $\mathrm{H} \quad 1.008 \times 2=2.016$

Atomic Weighe $015.999 \times 1=15.999$

Atomic Weight $\mathrm{H}_{2} \mathrm{O}=18.015$

Mass Fraction $\mathrm{H}-2.016 / 18.015=0.1119$

Mass Fraction $0=15.999 / 18.015-0.8881$

The structure of the composites section with water would then be:

START_COMPOSITES $\langle C r\rangle$

WATER $\langle c r>$

$\mathrm{H}\langle\mathrm{cr}>$

$0.1119\langle\mathrm{cr}\rangle$

$00.8881<c r\rangle$

END WATER. . <cr $>$

othere composites

...

END COMPOSITES $\langle$ Cr $>$ 


\section{Filters Section}

This is the final section of the input file which defines the beamline configuration for which the calculations are to be done. It must be a logical progression of filters - scatterers - absorbers - apertures whose placement in the input file should follow the placement in the beamline in increasing distance from the source point.

The principal command lines here are the 'filters'. A filter comnand forces the calculation of the spectrum as a function of the energy and vertical opening which can pass through the filter. also calculated is the spectrum which is scattered by that filter both coherently and inelastically ( Compton Effect).

Another useful aspect of the program is its capability to calculate the amount of Compton scattered radiation which will pass through a wall of arbitrary composition at some fixed angle to the direct beam. The scatterer is assumed to be an isotropic point source.

Also, the filtered-direct and filtered-scattered beams can be used as sources for dose calculations in a medium such as that representative of human tissue. In the case of the filtered direct beam, this is useful, for example, in determining the effectiveness of photon shutters, backstops, etc. In the case of the transmitted Compton scattered spectrum, this useful for assessing the effectiveness of shlelding surrounding beamline components expected to generate large amounts of scattered raiation, such as monochromators, filter, apertures, etc.

Note that any filter element or material used here must have been previously defined in the elements or composites section of the input file. To not do so will result in an error message and fatal abortion of the program. Also note that the elemental filters must be upper case and the case of composites defined must match that in the composites section. It is good practice to use upper case throughout the input file.

This section must be started by the START_FILTERS command and cerminated by the END_FILIERS command. 


\section{The Filter Comend}

The use of this command results in the calculation of the transmission through a filcer material, the total elastic and inelastic scatter from that filter, the power absorbed in the filter and the power transmitted through the filter.

The power absorbed in a filter makes use of the transmission through the previous filter in order to perform the calculation.

The absorbed power distribution as function of opening angle,

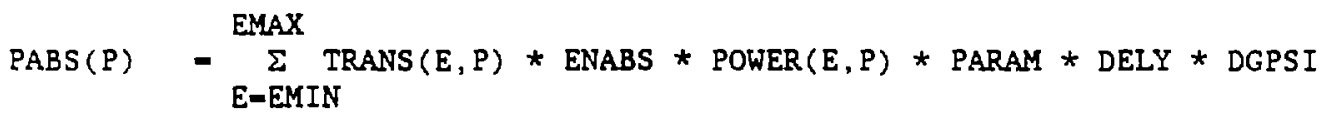

EMIN

EMAX

TRANS ( $E, P)$

POWER (E, P)

PARAM

DELY

DGPSI

ENABS

ENABS1

ENABS 2

SELFABS

REABS 1
- minimum phuton energy

- maximum photon energy

- the transmission factor through the previous filters as a function of energy $E$ and opening angle $P$

- the incident synchrotron power distribution as a function of $E$ and $P$

- a number which scales the result into a power

- the delta $E$ increment divided by the critical energy EC

- the delta gamma-psi increment in radians

$-1-\operatorname{EXP}(-($ ENABS1+ENABS 2$) *$ THICK * DENS $)$

$=\operatorname{EMU}(E)+\operatorname{SIGEN}(E)$

- SELFABS * (REABSI + REABS2)

- an input number between 0 and 1 which is used to estimate the additional power absorption due to the filter reabsorbing its own fluorescence and scattered radiation

$=(\operatorname{SIGCOH}(E)+\operatorname{SIGINC}(E)-\operatorname{SIGEN}(E))$ if the energy $E$ is within delta $E$ of the fluorescense energy $E F$, else 


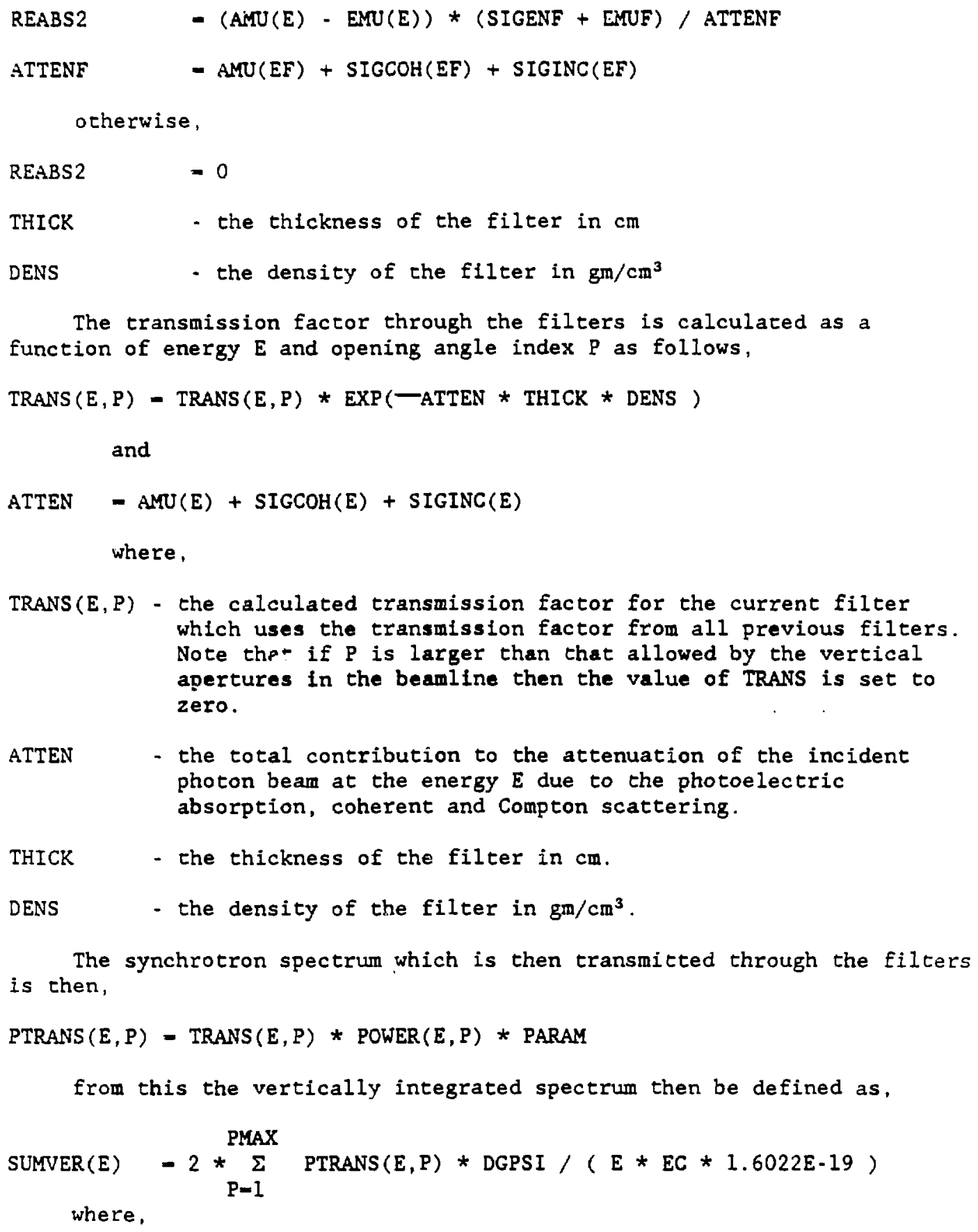

The transmission factor through the filters is calculated as a function of energy $E$ and opening angle index $P$ as follows,

The synchrotron spectrum which is then transmitted through the filters $\operatorname{PTRANS}(E, P)=\operatorname{TRANS}(E, P)$ * POWER $(E, P)$ * PARAM

from this the vertically integrated spectrum then be defined as, PMAX

$\operatorname{SUMVER}(E) \quad-2 * \sum_{P=1} \operatorname{PTRANS}(E, P) *$ DGPSI $/(E * E C * 1.6022 E-19)$ where, 
The structure of the filter command is as follows:

fil $<c r>$

thick, dens, self-abs, dist, vert-hght<cr>

where,

fil - name of an element or composite defined above

thick - thickness of the filter in millimeters

dens - density of the filter in grams/cubic centimeter

self-abs - number between 0 and 1 which indicates the estimated amount of self absorption the filter has for its own fluorescence scatter

dist - the distance from the source point to the midpoint of the filter being considered

vert-hght - the vertical half height of any hard aperture present at this filter in millimeters from the midplane of the synchrotron source

An example of an $10 \mathrm{mil}$ thick, $1 \mathrm{cn}$ high Beryllium window at 10 meters from the source point with worst case power loading would then be entered as :

$\mathrm{BE}<\mathrm{Cr}>$

$0.254,1.85,1.0,10000,5<c r>$

An example of a vertical aperture again with $1 \mathrm{~cm}$ full height at 10 meters would be defined as follows (note that in the case of an aperture the element or composite used is immaterial as long as it has been previously defined).

$B E<C r>$

$0,1.85,1.0,10000,5<c r>$

Note that here the thickness is zero, which makes this filter act as a vertical aperture not a filtering element. 
The plotting commands are intended to be used inline with the filter commands to show the transmitted or scattered spectra from the various filter materials.

Currently the type of plotting which is done requires the use of a program called MAPPER(4) MAPPER is a program developed at Los Alamos National Laboratory using the DISSPLA(4) graphics package. MAPPER uses as input an ASCII file such as written by this program to generate plots on a wide variety of devices supported by the DISSPLA package. Since the file is easily editable, modifications to the plots can be made without recompiling a program, as would be necessary with most graphics packages. Since the plotting only occurs in the PHOTON subroutines, the program could be modified to generate plots using other graphics packages available.

PLOT plots the vertically integrated transmitted spectrum per eV through a filter. PLTBW plots the vertically integrated transmitted spectrum per some percent bandwidth through a filter. IPLOT plots the total incoherently scattered (Compton scattered) spectrum per eV from a filter. CPLOT plots the total coherently scattered spectrum per eV from a filter. ICPLT plots both the coherent and incoherent spectra on the same plot and SPLOT plots the sum of the coherent and incoherent spectra.

Rules for use:

1) commands must come after at least one filter, though it may be of zero thickness.

2) these commands use values set in the parameters section.

a) the horizontal energy axis is linear for the PLOT, IPLOT, CPLOT, ICPLT and SPLOT commands with minimum value of zero energy and maximum value set by MAXIMUM ENERGY IN KEV.

The PLTBW energy axis is logarithmic with minimum and maximum values set by the MINIMUM_ENERGY_IN_KEV and

MAXIMUM_ENERGY_IN_KEV.

b) the spectrum is scaled by the two values CURRENT_FOR_PLOTS and HORIZONTAL_MRAD_FOR_PLOTS and these valies appear on the plots ( note: the default values for both is 1.0 if not set).

c) if SAME_SCALE_FOR_PLOTS has not been set the vertical axis is logarithmic with a maximum value set by the spectra maxima and the number of cycles set by VERTICAL_AXIS_LOG_CYCLES. 
if SAME_SCALE_FOR_PLOTS has been set then, the first plot command encountered will be scaled as previously described above; however, all subsequent plots will retain the same scale for that plot type (ie. the scale set by the first PLTBW command will only affect subsequent PLTBW commands, not the PLOT, etc commands.)

As an example, we will plot 'everything' following our previous example of a Beryllium window filter,

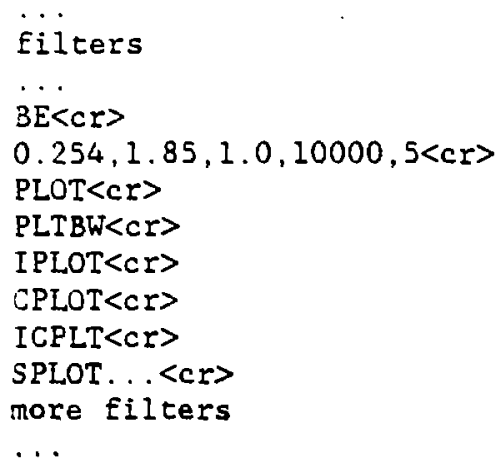


The NICK command is used after a filter in order to estimate the surface dose of radiation some material (presumably human tissue) would receive in the direct bcam after a filter or filters. This command works much the same was as the WHOM command, though it uses the transmitted spectrum in order to perform the dose calculation.

The name of this command is derived from Nicholas Gmur, who helped immensely in the development of this program. It somehow seems fitting that he should have this commin it named after him (Who should we put in the direct beam? ... Why, NICK of course!).

The dose in NICK is calculated as follows:

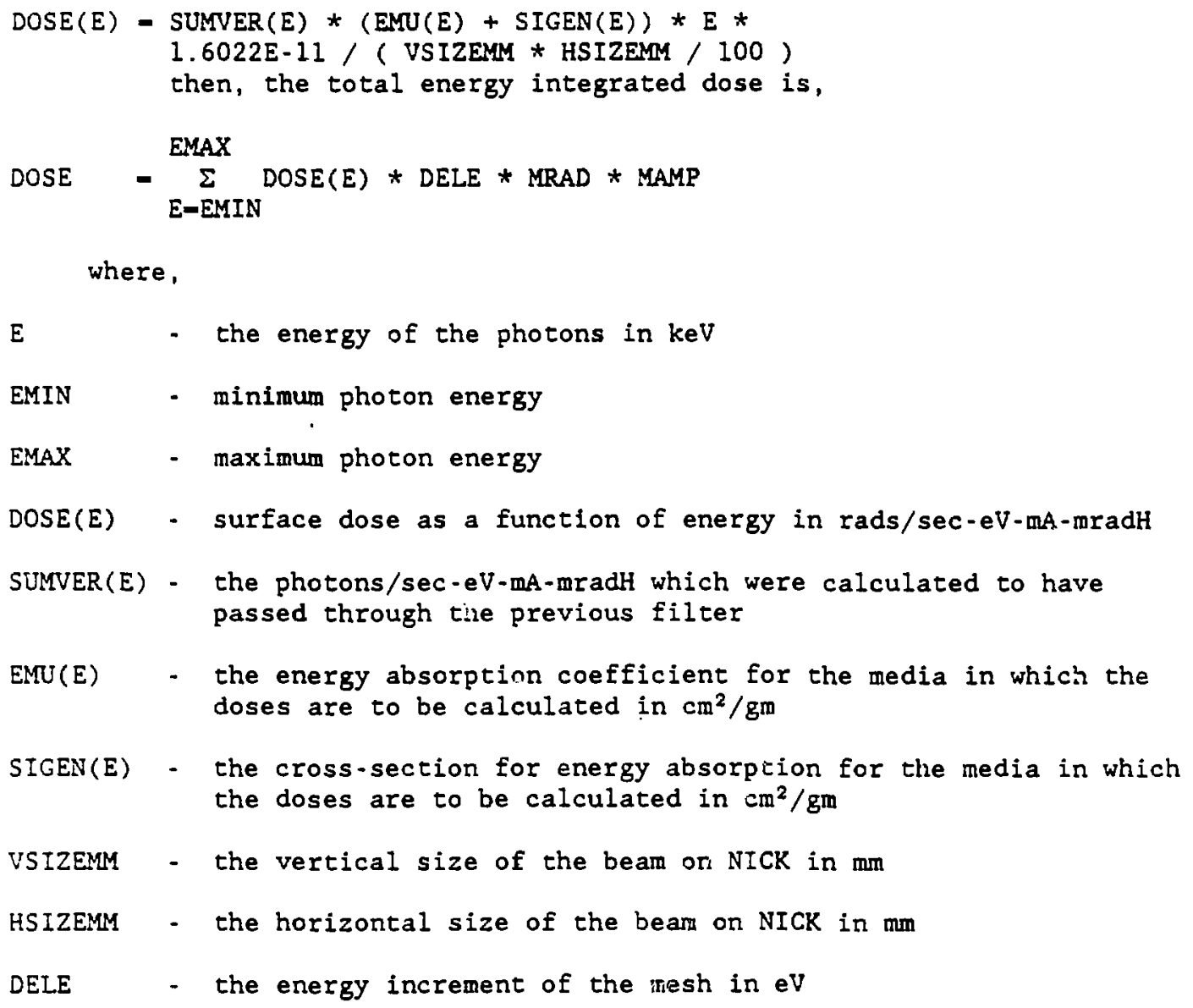


To be implemented in the program, the NICK command must follow a filter command. It must follow the syntax.

1) the first line contains the NICK<cr> command

2) the second line contains the number of horizontal milliradians, the number of milliamps ring current, the vertical size of the beam in millimeters and the horizontal size of the beam in millimeters<cr>

3) any number $(<30$ ) of materials for which the surface dose is to be calculatcd. NICK will calculate the dose absorbed in each independently using the same incident flux for each. These materials must have been previously defined in the elements or composites section.

4) the terminator is the END_NICK command

For example (5), consider the case of calculating the dose absorbed in the standard tissue ICRU4 and, under the same conditions, the absorbed dose in BONE and WATER. The beam conditions are 5 horizontal milliradians incident on the scatterer and 200 milliamps ring current and a $10 \times 10 \mathrm{~mm}$ beam size. Note that the composite materials ICRU4, BONE, and WATER must have been defined in the composites section. The following sequence is then used,

...

filter commands

...

NICK $<c r>$

$5,200,10,10<c r>$

ICRU4<Cr>

BONE<cr>

WATER $<c r>$

END_NICK<cr $>$

...

other filter or plot commands

...

This will result in the dose calculated for each material being written to the output file in rads/sec, millirads/hour and millirads/year. 
The WALL command is used after a filter command in order to calculate the amount of scattered radiation from that filter which subsequently passes through a set of materials which comprise a wall. This section takes the total inelastically scattered radiation from the filter. It then makes the following assumptions:

1) that the scattering is isotropic ( the real inelastic scattering is not isotropic but varies from a maximum in the forward direction to about one-half the maximum in the 90 degree direction at $100 \mathrm{keV}$ )

2) that the total source of scattering is a point source. The scatter at the wall distance is assumed to have dropped by a $1 / R^{2}$ factor which is true only for a point source.

The radiation which is incident upon the filter is scattered according to the incoherent cross-section SIGINC(EPRIME), and the incident energy spectrum used is such that when this radiation at the EPRIME energy is Compton shifted through an angle set by COSTH (defined in the program currently to be cosine(90 degrees), that the resulting scattered photon energy is $E$. Here $E$ is a value which matches the linear energy mesh from EMIN to EMAX and will be referred to as the 'original' energy mesh. The non-linear mesh resulting from the transformation of $E$ to EPRIME will be referred to as the 'Compton' energy mesh. The relation between the original energy mesh value $E$ and the Compton value is given by,

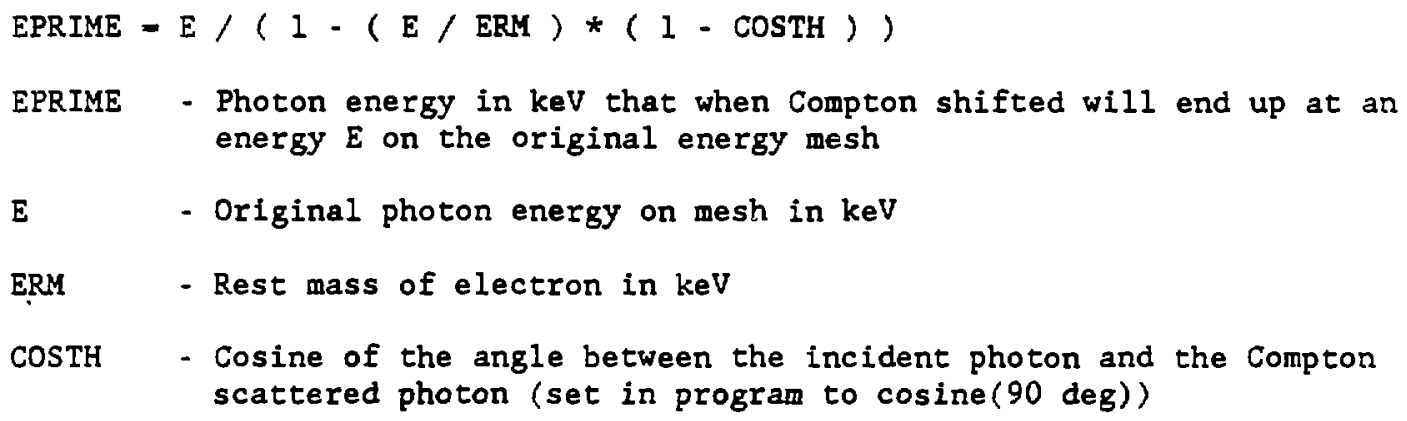
energy $E$ on the original energy mesh

E - Original photon energy on mesh in $\mathrm{keV}$

ERM - Rest mass of electron in $\mathrm{keV}$

COSTH - Cosine of the angle between the incident photon and the Compton scattered photon (set in program to cosine( 90 deg))

Any spectrum through a filter is always calculated with these two energy meshes. The spectrum which is used for any output is the normal energy mesh. The second Compton mesh is used solely for the instances when the photons are Compton scattered by some material. This spectrum along with a set of absorption coefficients and cross sections calculated at these 
energies are used to calculata properly the spectrum up to any scatterer. Then to properly calculate the scattered spectrum the Compton energy spectrum is scattered by the inelastic cross sections at the Compton energies and the resulting spectrum is at the original mesh energies. The inelastic spectrum is then found in the following way:

$\operatorname{ATTI}$ - AMU(EPRIME) + SIGCOH(EPRIME) + SIGINC(EPRIME)

$\operatorname{ISCAT}(E)=\operatorname{SPECT}(E P R I M E)$ * $\operatorname{SIGINC}(E P R I M E) *(1-\operatorname{EXP}(-\operatorname{ATTI}$ * THICK * DENS) ) / ATTI

where,

ISCAT - the scattered flux in photons/eV-mradH-mA from the filter element on $E$ energy mesh

SPECT - the incident flux in photons/ev-mradH-ma upon the filter element with the EPRIME energy mesh

ATTI - total attenuation of the photon beam at the EPRIME energy

AMU - the photoelectric maisic absorption coefficient in $\mathrm{cm}^{2} / \mathrm{gm}$

SIGCOH - the cross section for coherent scattering in $\mathrm{cm}^{2} / \mathrm{gm}$

SIGINC - the cross section for incoherent scattering in $\mathrm{cm}^{2} / \mathrm{gm}$

THICK - the thickness of the filter - scatterer in $\mathrm{cm}$

DENS - the density of the fllter - scatterer in $\mathrm{gm} / \mathrm{cm}^{3}$

Once the WALL command has been called in the input file, this scattered spectrum is then used to estimate the scatter through the subsequent wall as follows:

$\operatorname{SCATTER}(E)=\operatorname{ISCAT}(E) *(1 /(4 * \mathrm{PI} * \operatorname{DISTWALL}$ **2) $)$

where,

SCATTER(E) - the scattered spectrum incident upon the wall in photons/eV$\operatorname{mradH}-\mathrm{mA}-\mathrm{cm}^{2}$

DISTWALL - the distance to the wall in $\mathrm{cm}$ 
It is then this spectrum which is subsequently attenuated by the wall materials. This attenuation is done by passing the scatter through each shielding wall material.

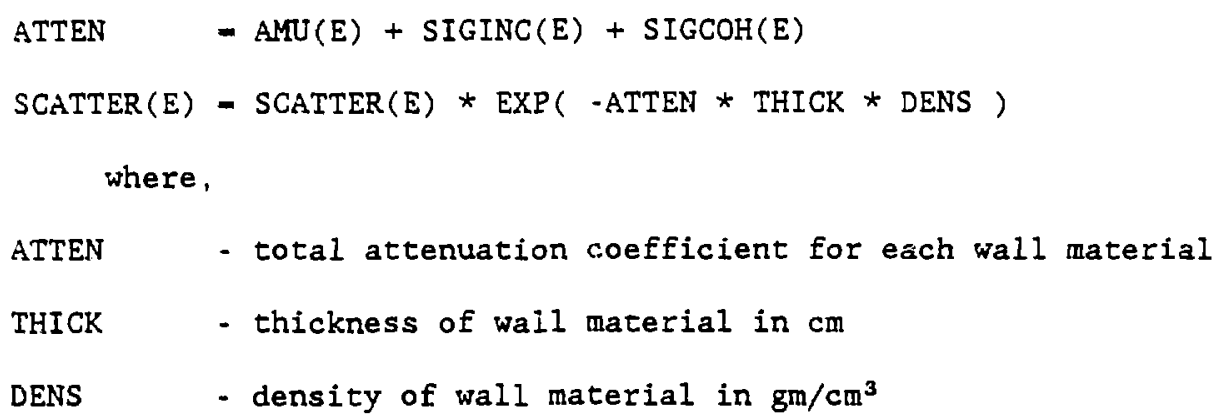

For each material in the wall list, the above attenuation of the scatter is calculated until all wall materlals have been accounted for.

The WALI command automatically creates a plot in the plot file containing the transmitted spectrum through the wall with units of photons $/ \mathrm{eV} \cdot \mathrm{cm}^{2}$

The structure of the command then has the following components,

1) the WALL<cr> command begins the sequence,

2) the second line contains the distance in millimeters from the scatter point to the point outside the wall where any dose calculation is to be done

3) the next lines contain,

a) wall material name which must have been defined in the elements or composites section<cr $\rangle$

b) the thickness in millimeters and density in $\mathrm{gm} / \mathrm{cm}^{3}$ for that wall material

This is repeated until all wall materials are included in the list.

4) the wall is terminated with the END_WALL<cr> command.

For example, consider the case of calculating the transmitted scatter spectrum from a Silicon monochromator crystal 15 meters from the source point through a wall 1 meter away composed of $1 / 8$ inch steel. We might use the following sequence of commands, 
$S I<c r>$

$50,2.33,0,15000,5<c r\rangle$

WAIL $<c r>$

$1000,0<c r>$

STEEL<Cr>

$3.175,7.8<c r>$

END WALL $<c r>$

other whom, filter or plot commands

Generally, the command following the wall commands is the WHOM command so that the dose arising from the scatter through the wall can be calculated. This command will next be considered. 
The WHOM command is used after a wall in order to estimate the surface dose of radiation some material (presumably human tissue) would receive outside the shielding wall.

This section of the program receives the scattered spectrum from the previous wall program section in which the distance to the wall and its construction is defined. The wall section will then have calculated the scattered spectrum in photons per sec - eV - mA -horizontal mrad - $\mathrm{cm}^{2}$ passing through the wall. What the whom section then does is to calculace the surface dose arising from absorption in materials at a specified number of horizontal milliradians and ring current.

The dose is calculated as follows:

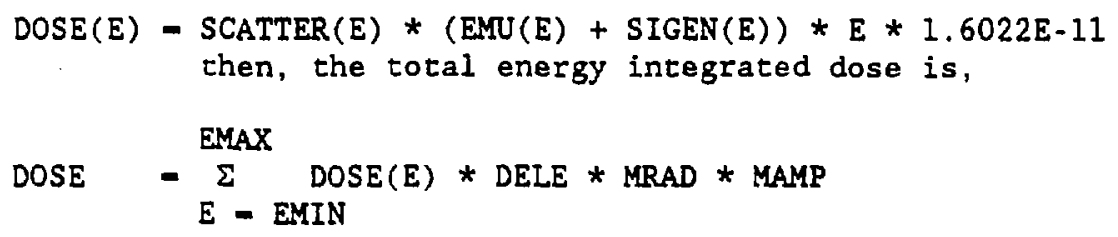


To be implemented in the program, the WHOM command must follow a the WALL command sequence. It must follow the syntax,

1) the first line contains the wHOM<cr> command

2) the second line contalns the number of horizontal milliradians and number of milliamps ring current<cr>

3) any number $(<30$ ) of materials for which the surface dose is to be calculated.

WhOM will calculate the dose absorbed in each independently using the same incident flux for each. These materials must have been previously defined in the elements or composites section.

4) the terminator is the END_WHOM command

For example, consider the case of calculating the dose absorbed in the standard tissue ICRU4 and, under the same conditions the absorbed dose in BONE and WATER. The ring conditions are 5 horizontal milliradians incident on the scatterer and 200 milliamps ring current. Note that the composite materials ICRU4, BONE, and WATER must have been defined in the composites section. The following sequence is then used,

\section{WALL<Cr>}

...

wall commands

$\ldots$

END_WALL<cr>

WHOM $\overline{\mathrm{C}} \mathrm{Cr}>$

$5,200<c r>$

ICRU $4<c r>$

BONE<Cr $>$

WATER $<c r>$

END_WHOM<Cr>

$\cdots$

other filter or plot commands

$\ldots$

This will result in the dose calculated for each material being written to the output file in rads/sec, millirads/hour and millirads/year. 


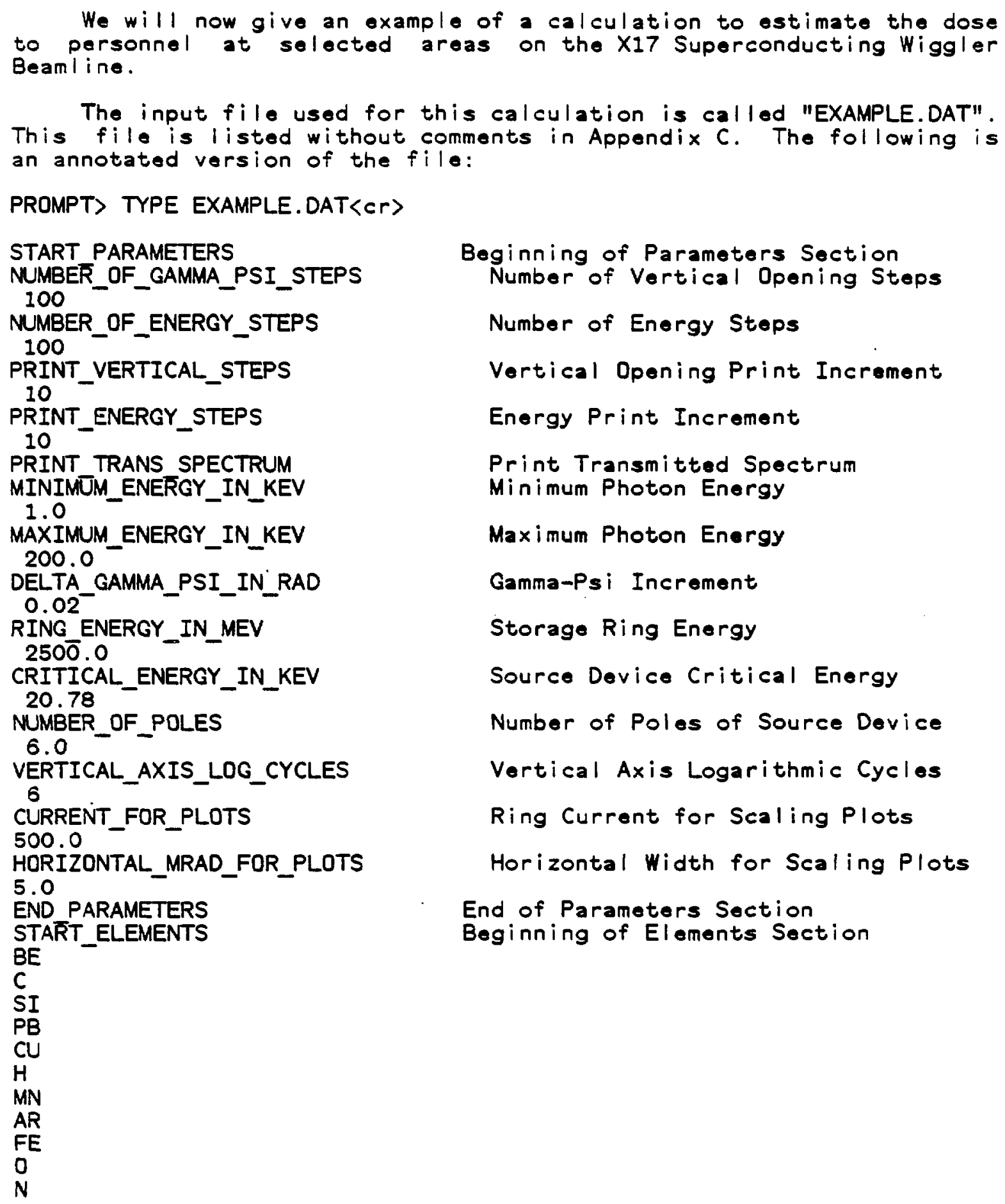

We will now give an example of a calculation to estimate the dose to personnel at selected areas on the X17 Superconducting Wiggler Beamline.

The input file used for this calculation is called "EXAMPLE.DAT". This file is listed without comments in Appendix $C$. The following is an annotated version of the file:

PROMPT > TYPE EXAMPLE.DAT〈Cr〉

START PARAMETERS

NUMBER_OF_GAMMA_PSI_STEPS 100

NUMBER_OF_ENERGY_STEPS 100

PRINT_VERTICAL_STEPS 10

PRINT_ENERGY_STEPS 10

PRINT TRANS SPECTRUM MINIMUM_ENERTGY_IN_KEV 1.0

MAXIMUM_ENERGY_IN_KEV 200.0

DELTA_GAMMA_PSI_IN_RAD 0.02

RING ENERGY IN MEV $250 \overline{0} .0$ CRITICAL_ENERGY_IN_KEV 20.78

NUMBER OF POLES

6.0

VERTICAL_AXIS_LOG_CYCLES 6

CURRENT_FOR_PLOTS 500.0 HORIZONTAL MRAD_FOR PLOTS 5.0

END PARAMETERS

STARTT_ELEMENTS

$B E$

$C$

SI

PB

CU

$\mathrm{H}$

MN

AR

FE

0

N

Beginning of Parameters Section Number of Vertical Opening Steps

Number of Energy Steps

Vertical Opening Print Increment

Energy Print Increment

Print Transmitted Spectrum

Minimum Photon Energy

Maximum Photon Energy

Gamma-Psi Increment

Storage Ring Energy

Source Device Critical Energy

Number of Poles of Source Device

Vertical Axis Logarithmic Cycles

Ring Current for Scaling Plots

Horizontal Width for Scaling Plots

End of Parameters Section

Beginning of Elements Section 


\section{END ELENENTS}

START_COMPOSITES

ICRU4

$\mathrm{H}$

.1000

C

.1490

N

.0350

0

.7160

END ICRU4

STEEL

FE

.9954

$\mathrm{C}$

.0006

MN

.0040

END STEEL

END- COMPOSITES

START_FILTERS

CU

$0.0,8.92,1.0,10000.0,7.50$

PLOT

C

$.391,2.1,1.0,12510.0,40.0$

BE

$0.508,1.848,1.0,12810.0,40.0$

PLOT

NICK

$5,500,5,65$

ICRU4

END NICK

SI

$50.0,2.33,1.0,23000.0,40.0$

WALL

1000.0

STEEL

$6.35,7.8$

PB

$6.35,11.4$

END WALL

WHOM

5,500

ICRU4

END WHOM

WALL

1000.0

STEEL

$0,7.8$

END WALL

WHOM

5,500

ICRU4
End of Elements Section

Start of Composites Section

Begin a Composite - ICRU4

Element Hydrogen

Hydrogen Mass Fraction in ICRU4

Element Carbon

Carbon Mass Fraction in ICRU4

Element Nitrogen

Nitrogen Mass Fraction in ICRU4

Element Oxygen

Oxygen Mass Fraction in ICRU4

End of Composite - ICRU4

Begin a New Composito - STEEL

End of Composite - STEEL

End of Composites Section

Start of Filters Section

Cu Aperture - Zero Thickness

th ick, dens, self-abs, dist, vert-height

Plot the Transmitted Spectrum

Graphite Filters

$0.391 \mathrm{~mm}$ total thickness

Beryllium Windows (2)

$20 \mathrm{mil}$ totel thickness

Plot the Transmitted Spectrum

Calculate Absorbed Dose in Direct Beam $5 \mathrm{mradH}, 500 \mathrm{~mA}, 5 \mathrm{~mm}$ height, $65 \mathrm{~mm}$ width Dose Medium is ICRU4

End of Direct Beam Dose Calculation

Next Filter - Silicon Monochromator $50 \mathrm{~mm}$ thick to generate maximum scatter

Calculate the Scatter through a Wall

Wall is $1000 \mathrm{~mm}$ from Scatter Point

First Wall Material - STEEL

$6.35 \mathrm{~mm}$ thick, $7.8 \mathrm{gm} / \mathrm{cm} \neq * 3$ density

Next Wall Material - Lead (PB)

$6.35 \mathrm{~mm}$ thick, $11.4 \mathrm{gm} / \mathrm{cm} * 3$ density

End of Shield Woll

Calculate Absorbed Dose behind Wall

for $5 \mathrm{mrad}$ horiz. and $500 \mathrm{~mA}$

ICRU4 Dose Material

End of Dose Calculation

Try a Different Wall Composition

Again $1000 \mathrm{~mm}$ from Scatter Point

First Wall Material - STEEL

Zero Thickness - No Attenuation

End of Shield Wall

Calculate Absorbed Dose with NO Wall

5 mrad horiz. and $500 \mathrm{~mA}$

ICRU4 Dose Material 
END WHOM

END_FILTERS
End of Dose Calculation End of Filters Section and end of the input file.

With this as an input $f \mathrm{i}$ le we can now run PHOTON. The following is the output to the terminal when PHOTON is run:

PROMPT> RUN PHOTON<Cr>

WHAT INPUT FILE NAME?

EXAMPLE.DAT〈Cr〉

WHAT OUTPUT FILE NAME?

EXAMPLE. OUT $\langle C r\rangle$

WHAT PLOT FILE NAME?

EXAMPLE.PLT〈CT〉

PARAMETER PRINT_TRANS POWER WAS NOT SET

DEFAULT VALUE $=$ - FALSE.

PARAMETER PRINT_POWER SPECTRUM WAS NOT SET

DEFAULT VALUE $=$-FALSE.

PARAMETER PRINT_SCATTERED_SPECTRUM WAS NOT SET

DEFAULT VALUE $=$ - FALSE.

PARAMETER PLOT ON SAME SCALE WAS NOT SET

DEFAULT VALUE $\equiv$.FALSE.

SYNCHROTRON SPECTRUM CALCULATED
ABSORBER.DAT read in OK
Material BE absorption-cross sections calculated
Material C absorption-cross sections calculated
Material SI absorption-cross sections calculated
Material PB absorption-cross sections calculated
Material CU absorption-cross sections calculated
Material H absorption-cross sections calculated
Material MN absorption-cross sections calculated
Material AR absorption-cross sections calculated
Material FE absorption-cross sections calculated
Material O absorption-cross sections calculated
Material N absorption-cross sections calculated
Material AIR absorption-cross sections calculated
Material ICRU4 absorption-cross sections calculated
Material STEEL absorption-cross sections calculated
Transmission through filter CU being calculated
Transmission through filter C being calculated
Transmission through filter BE being calculated
Absorbed Surface Dose in ICRU4 being calculated
Absorbed Surface Dose in SI being calculated
Transmission through filter SI being calculated


Transmission through wall STEEL being calculated Transmission through wall PB being calculated Absorbed Surface Dose in ICRU4 being calculated FORTRAN STOP

The information typed on the terminal screen is intended to keep the user informed (amused) while the program is executing and may assist in debugging in case of a failure. The calculation of the incident spectrum will take the most time (about 1 minute on a MicrovaX II).

Assuming the program has successfully executed, then the output $f i l e s$, EXAMPLE. OUT and EXAMPLE.PLT have been written. To find out the contents of these files, then...

PROMPT> TYPE EXAMPLE. OUT

$\begin{array}{ccc}\text { EMIN } & \text { EMAX } & \text { DGPSI } \\ 1.000 & 200.000 & 0.020 \\ \text { ELEN } & \text { EC } & \text { POLES } \\ 2500.000 & 20.780 & 6.000 \\ \text { VERTICALLY } & \text { INTEGRATED POWER IN } \mathrm{W} / \mathrm{mradh}-\mathrm{mA} \\ 1.9128 & \end{array}$

MATERIAL, CODE NO

\begin{tabular}{|c|c|c|c|c|c|}
\hline $\begin{array}{c}\text { ENERGY IN KEVV } \\
1.00000\end{array}$ & $\begin{array}{l}\text { AMU, } \\
598.47000\end{array}$ & $\begin{array}{r}\text { EMN, } \\
598.43717\end{array}$ & $\begin{array}{l}\text { SIGCOH, } \\
0.58529\end{array}$ & $\begin{array}{l}\text { SIGINC, } \\
0.03415\end{array}$ & $\begin{array}{c}\text { SIGEN }(C M * * 2 / G M) \\
0.00009\end{array}$ \\
\hline etc & • & • & - & - & . \\
\hline
\end{tabular}

The complete listing of this $f i l e$ is in Appendix $C$. Most of the numbers in this file are self-explanatory or have been explained in earlier sections of the paper.

The plot file which is generated is a file which contains MAPPER commands. This is an ASCII $f i l e$ and can be typed or edited. A listing of this $f i l e$ is included in Appendix $C$. In order to generate a plot of using MAPPER, the following commands can be used:

PROMPT〉 mapper $i=e x a m p l e . p \mid t\langle c r\rangle$

PLOT DEVICE = toktronix, 4014,2 
This will cause plotting to occur at the terminal which is assumed have Tektronix 4014 emulation capabilities. Other plotting devices are allowed, which on the BNL Computing Center's VAX, BNLCL3, are:

$\begin{array}{lllll}\text { AED } & \text { COMP8O } & \text { HPACKARD } & \text { JUPITER7 } & \text { OKIDATA } \\ \text { RAMTEK } & \text { TEKTRONIX } & \text { TALARIS } & \text { VERSATEC } & \text { APPLE }\end{array}$

DATAPRODUCTS BSIF

When using PHOTON on, this VAX the simplest way to get a hardcopy of the plot is th use the TALARIS laser printer. This can be done by:

PROMPT > mapper $i=e x a m p l e . p \mid t\langle c r\rangle$

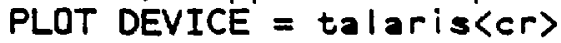

Do you want Tektronix output to appear on the screen? $(y) n\langle c r\rangle$

ELAPSED TIME $=000: 02: 32.93$

CPU TIME $=0: 01: 01.23$

BUFFERED $I / O$ COUNT $=623$

DIRECT I $/ 0$ COUNT $=22$

PAGE FAULT COUNT $=793$

PROMPT $\rangle$ tplot $\langle c r\rangle$

The last command (TPLOT) will plot an intermediate file named TALARIS.LIS on the self service laser printer. Using the command, QPLOT, will plot on the high speed laser printer in the computing facility and the output will appear in the boxes. The plots generated by the EXAMPLE.PLT file using MAPPER with the output to the laser printer is shown in Appendix $C$. 


\section{Concluaton}

PHOTON has proven very useful in the develpment of the X17 superconducting wiggler beamline. Its use has determined the shielding required from the wiggler device to the very end of the beamline in the hutches and angiography section. Doses calculated by this program have been compared with experimental results from conventional beinging magnet beamlines with great success. In each case the program consistently overestimated the dose by factors ranging from 2 to 10 . The reason for this overestimation is understood and was not refined further in the program in order to maintain some level of safety in the shielding calculations.

PHOTON should prove useful in the design of any beamline. It has the ability to calculate power deposited and spectra transmitted through nearly arbitrary beamline configurations. As well, calculation of the scattered radiation doses through shielding walls makes it a very powerful tool in assessing the overall safety of the beamline and the possible measures which can be taken to improve shielding.

\section{Acknowledgements}

We would like to thank Elke Brauer, without whose help we would not have completed this project and trusted its results. This work was supported by DOE contract DE-ACO2-76CH00016.

\section{References}

(1) P. Suoftti and W. Thomlinson. BNL Informal Report 34934 (1984).

[2] E. Brauer and $W$. Thomlinson. The Proceedings of the 5 th National Conference on Synchrotron Radiation Instrumentation, Univ. of Wisconsin-Madison, 1987, Nucl. Instr. and Meth. (to be published); BNL Informal Report 39541 (1987).

[3] D. Chapman, N. Gmur, N. Lazarz and W. Thomlinson. Proceedings of the 5 th Nat. Conf. on Synchrotron Radiation Instrumentation, Univ. of Wisconsin-Madison, 1987, Nucl. Instr. and Methods (to be published).

[4] MAPPER version 4.0, Graphics code developed at Los Alamos National Laboratory by David A. Dahl, to be used with Display Integrated Software System and Plotting Language (DISSPLA). DISSPLA is a proprietary software product of Integrated Software Systems Corporation, San Diego, CA (1977).

[5] D.W.O. Rogers, Health Phys. 46 (1984) 891. 
Appendix A

Photon: A Program for Synchrotron Radiation Dose Calculations

Presented at the Fifth National Conference on Synchrotron Radiation Instrumentation, University of Wisconsin-Madison, 1987. Submitted for publication in Conference Proceedings in NIM.
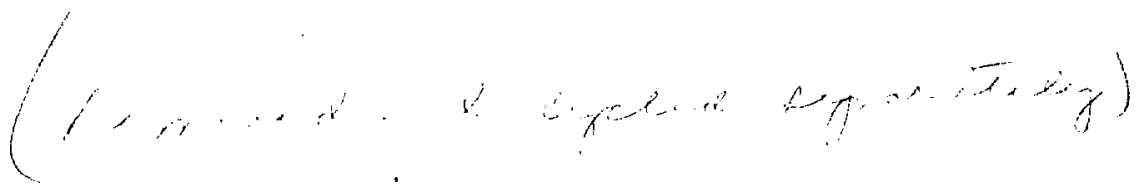
A Brief Description of the ABSORBER.DAT File

(N.F.Gmur and L.D. Chapman; May 1986)

(Updated Version Oct 1987 by LDC)

The ABSORBER.DAT file contains the parameters for determining the 1) mass absorption coefficients and the 2) scattering cross sections of some elements. These absorption coefficients and scattering cross sections are:

$$
\begin{aligned}
& \text { AMU(E) - the photoelectric absorption coefficient } \\
& \text { EMU(E) - the part of the photoelectric absorption } \\
& \text { coefficient which results in energy } \\
& \text { absorption in the material } \\
& \text { SIGCOH(E) - the total angularly integrated coherent } \\
& \text { or elastic cross-section } \\
& \text { SIGINC(E) - the total angularly integrated incoherent, } \\
& \text { inelastic, or Compton cross-section } \\
& \text { SIGEN(E) - the total cross-section for scattering which } \\
& \text { results in energy being deposited in the } \\
& \text { material }
\end{aligned}
$$

The current file contains data for the following elements:

$$
\text { Element } Z \text { Full Name }
$$

$\begin{array}{lll}\text { H } & 1 & \text { Hydrogen } \\ \text { HE } & 2 & \text { Helium } \\ \text { BE } & 4 & \text { Beryliium } \\ C & 6 & \text { Carbon } \\ \text { N } & 7 & \text { Nitrogen } \\ \text { O } & 8 & \text { Oxygen } \\ \text { AL } & 13 & \text { Aluminum } \\ \text { SI } & 14 & \text { Silicon } \\ \text { P } & 15 & \text { Phosphorus } \\ \text { S } & 16 & \text { Sulfur } \\ \text { AR } & 18 & \text { Argon } \\ \text { CA } & 20 & \text { Calcium } \\ \text { CR } & 24 & \text { Chromium } \\ \text { MN } & 25 & \text { Manganese } \\ \text { FE } & 26 & \text { Iron } \\ \text { NI } & 28 & \text { Nickel } \\ \text { CU } & 29 & \text { Copper } \\ \text { GE } & 32 & \text { Germanium } \\ \text { KR } & 36 & \text { Krypton } \\ \text { MD } & 42 & \text { Molybdenum } \\ \text { XE } & 54 & \text { Xenon } \\ \text { TA } & 73 & \text { Tantalum } \\ \text { PB } & 82 & \text { Lead }\end{array}$

Due to limitations of dimensioned variables in PHOTON.FOR, only a maximum of 30 elements may be listed in ABSORBER.DAT at the present time. 
The sources of the data for each of the elements are the following two reports:

Biggs, F. and R. Lighthill. 1971. Analytical Approximations for X-Ray Cross Sections II. Sandia National Laboratories, Albuquerque, NM 87185. Report number SC-RR-71 0507. 143 po.

Biggs, F, and R. Lighthill. 1972. Analytical Approximations for Total and Energy Absorption Cross Sections for Photon-Atom Scattering. Sandia National Laboratories, Albuquerque, NM 87185. Report number SC-RR-72 0685. 134 pp.

Original copies of these reports are held by Nicholas Gmur. Selected pages are attached to this description. If data are added to the ABSORBER.DAT file, they must be added in exactly the same format as those set out in the existing file.

The following sections describe the various portions of data for any of the elements. Please see the attached copy of the file for specific information (the element Beryllium is used here as an example).

Record Type A:

BE = Beryllium.

8 = absorption edge cuts (NEDGE).

4 = atomic number (ZET).

Record Type B:

$\begin{array}{llllllll}999.000 & 500.000 & 100.000 & 20.000 & 4.000 & 0.800 & 0.111 & 0.010\end{array}$

= numerical values of fitting intervals. Energies (in kev) are used in a spline fit for the absorption coefficients.

Record Type C:

$0.0005=$ effective K-fluorescence yield in keV (ETA). Values were obtained from W. Bambynek et al. October 1972.

Reviews of Modern Physics 44(4): 716-813.

0.1097 = average energy of $K-f$ luorescence in $k e V$ (EF).

$0.1115=\mathrm{K}$-edge in $\mathrm{keV}$ (EK).

0.4438 = atomic number/atomic weight $(Z A)$.

Record Type D:

= coefficients used for the spline fitting polynomial for the absorption coefficients between energy intervals 1 isted in Record Type B.

Record Type E: 
0.60225 = polynomial coefficient for the total coherent scattering cross-section; element independent.

4 = element atomic number (Z).

$0=$ remaining coefficients are element independent.

Record Type F:

= parameters associated with total coherent scattering crosssections.

Record Type G:

= break energies for the spline fit to the total coherent scattering cross-sections; element independent.

Record Type $\mathrm{H}$ :

= polynomial coefficient for the total incoherent scattering cross-sections; element independent.

Record Type I:

= parameters associated with the total incoherent scattering cross-sections.

Record Type J:

= break energies for the spline fit to the total incoherent scattering cross-sections; element independent.

Record Type K:

= polynomial coefficients for the incoherent scattering energy absorbtion cross-section; element independent.

Record Type L:

=.parameters describing the incoherent scattering energy absorption cross-section.

Record Type M:

= break energies for the spline fit to the incoherent scattering energy absorption cross-section; element independent. 
The Beryllium entry in the current ABSORBER.DAT file

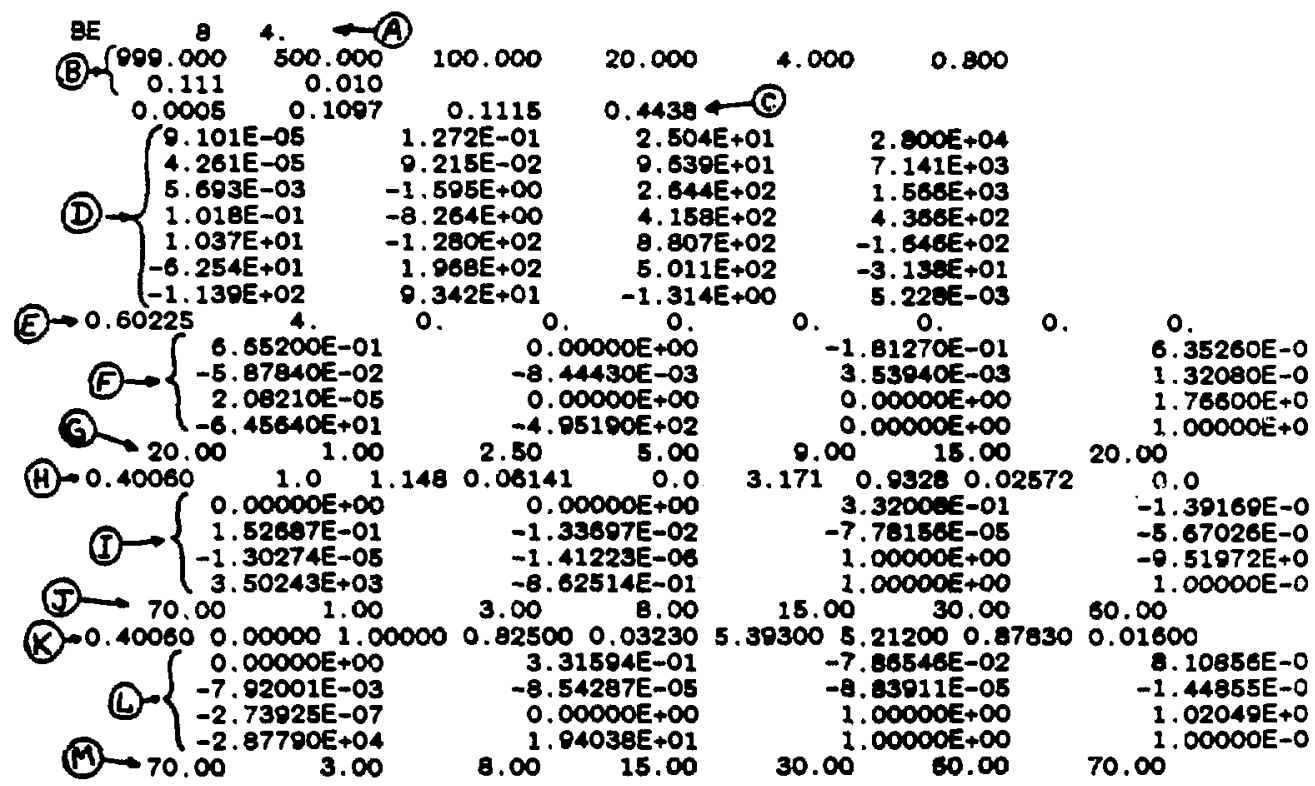

next elements...

It is strongly suggested that since this file is currently read by fixed formatted read statements that extreme care be taken in the entering of new elements to the file. If elements are added the values for the absorption coefficients and scattering cross sections should be independently checked against tables such as those in the International Tables for Crystallography. 
Appendix C:

The Input, Output and Plot Files

EXAMPLE. DAT

EXAMPLE. OUT

EXAMPLE. FLT

MAPPER PLOTS
Cl

CB

Cb

cB 


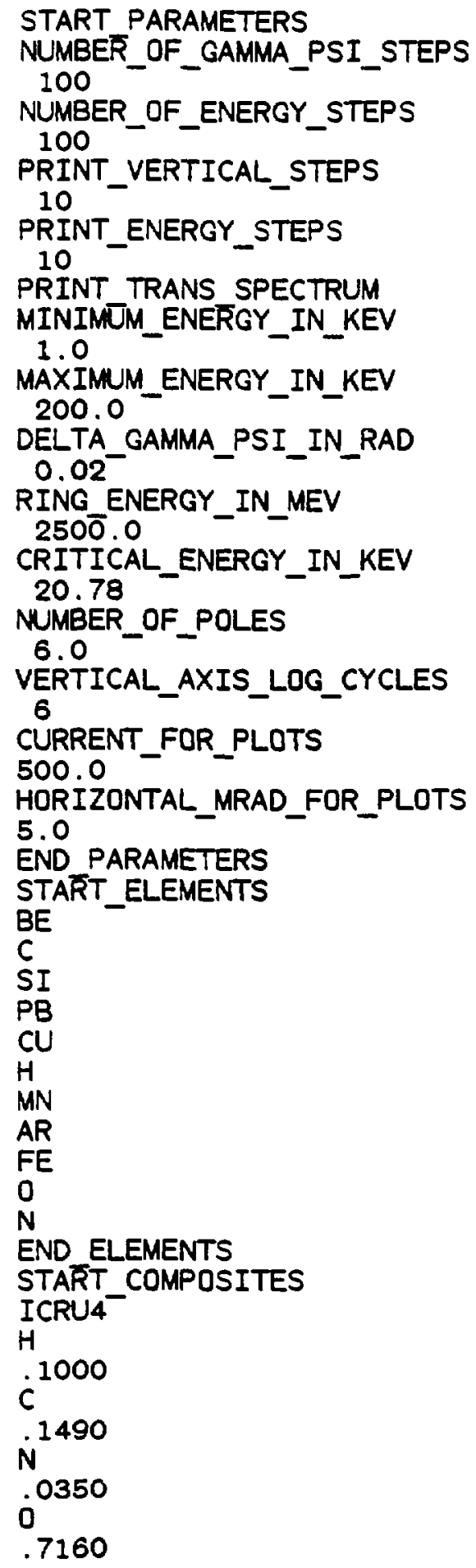




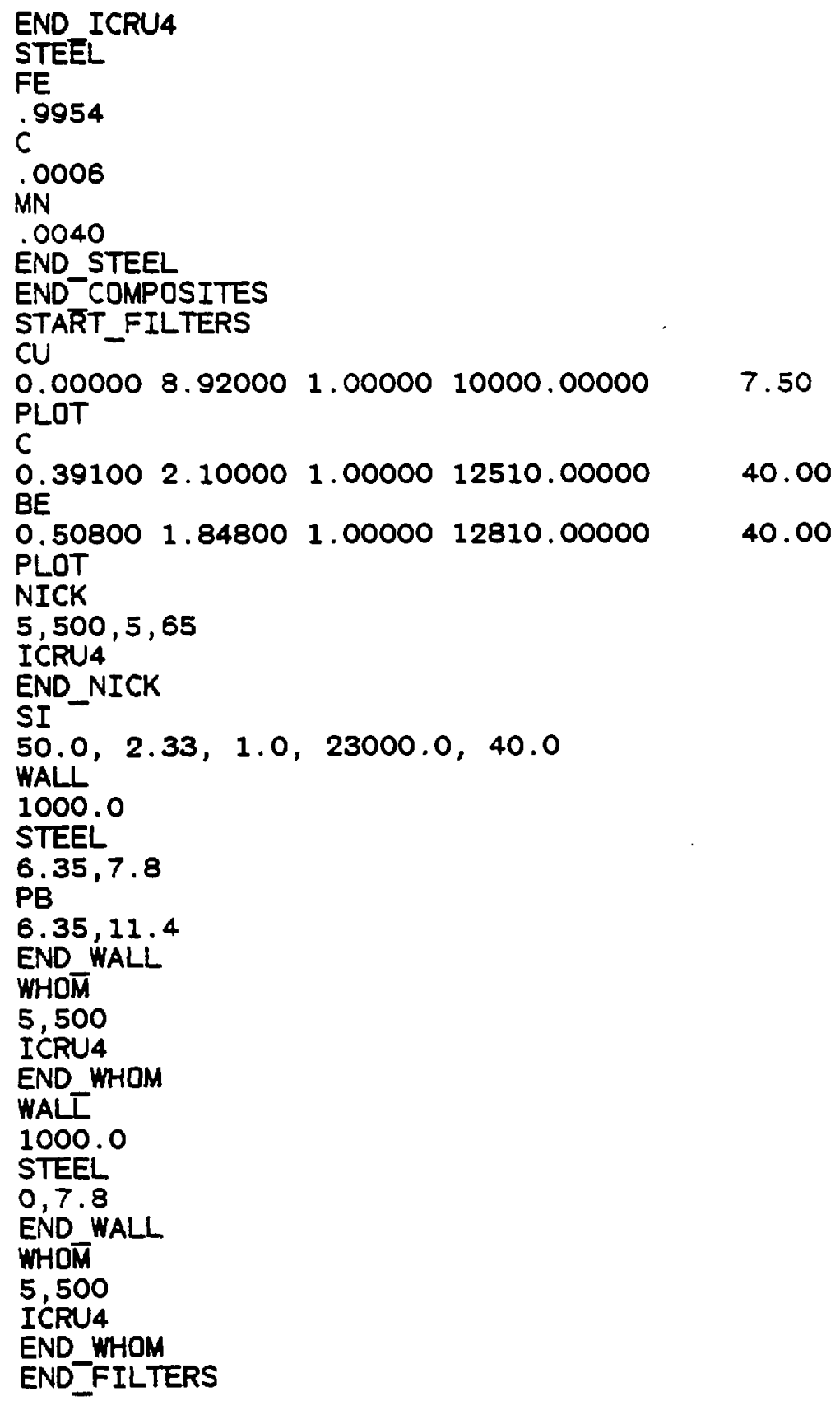




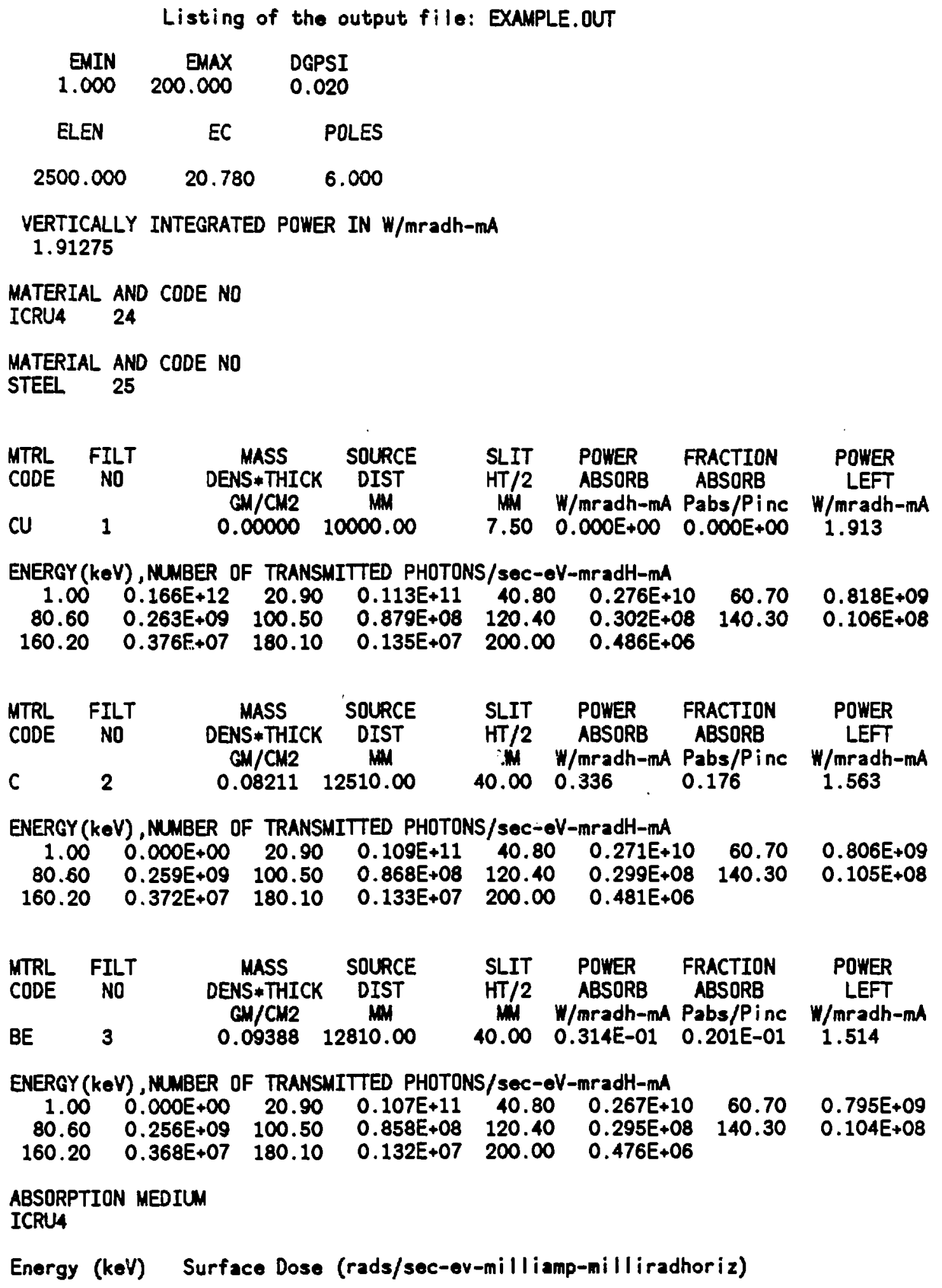


through a filter 12.8100 meters from the source point
$1.000000 .000000 \mathrm{E}+00$
20.90000 .446346
$40.8000 \quad 0.311092 E-01$
$60.7000 \quad 0.692774 E-02$
$80.6000 \quad 0.250024 E-02 \quad 100.500 \quad 0.104057 E-02 \quad 120.400 \quad 0.444532 E-03$
$140.300 \quad 0.189097 \mathrm{E}-03$
$160.200 \quad 0.795673 E-04 \quad 180.100 \quad 0.331098 E-04 \quad 200.000 \quad 0.136430 E-04$

All following doses are calculated for $500.000 \mathrm{mill}$ iamps and 5.00000 horizontal milliradians through the last filter 12.8100 meters from the source point

TOTAL MAXIMUM DOSE 1: rads/sec 2: $\mathrm{mrads} / \mathrm{hr} 3: \mathrm{mrads} / \mathrm{yr}$ $0.18868 E+09 \quad 0.67877 E+15 \quad 0.59501 E+19$

\begin{tabular}{|c|c|c|c|c|c|c|c|}
\hline $\begin{array}{l}\text { MTRL } \\
\text { CODE }\end{array}$ & $\underset{N O}{\text { FILT }}$ & $\begin{array}{c}\text { MASS } \\
\text { DENS } * \text { THICK } \\
\text { GM/CN2 } \\
11.65000\end{array}$ & $\begin{array}{c}\text { SOURCE } \\
\text { OIST } \\
\text { III } \\
23000.00\end{array}$ & $\begin{array}{c}\text { SLIT } \\
H T / 2 \\
40.00\end{array}$ & $\begin{array}{c}\text { POWER } \\
\text { ABSORB } \\
\text { W/mradh-mA } \\
1.46\end{array}$ & $\begin{array}{c}\text { FRACTION } \\
\text { ABSORB } \\
\text { Pabs/Pinc } \\
0.966\end{array}$ & $\begin{array}{c}\text { POWER } \\
\text { LEFT } \\
\mathrm{w} / \mathrm{mradh-m} \\
0.1617 E-01\end{array}$ \\
\hline
\end{tabular}

ENERGY (koV), MUMBER OF TRANSMITTED PHOTONS/soc-oV-mradH-mA

$\begin{array}{rrrrrrrr}1.00 & 0.000 E+00 & 20.90 & 0.228 E-09 & 40.80 & 0.119 E+07 & 60.70 & 0.217 E+08 \\ 80.60 & 0.205 E+08 & 100.50 & 0.106 E+08 & 120.40 & 0.457 E+07 & 140.30 & 0.185 E+07 \\ 160.20 & 0.727 E+06 & 180.10 & 0.232 E+06 & 200.00 & 0.109 E+06 & & \end{array}$

WALL MATERIAL STEEL of thickness $6.35000 \mathrm{~mm}$ and density $7.80000 \mathrm{gm} / \mathrm{cm} * * 3$ at a distance of 1.00000 moters from the scatter point

ENERGY (koV), TRANSUITTED PHOTONS/sec-ov-cm**2-mh-mradh

$\begin{array}{rrrrrrrr}1.00 & 0.000 E+\infty 0 & 20.90 & 0.000 E+\infty 0 & 40.80 & 0.260 E-03 & 60.70 & 0.721 E+01 \\ 80.60 & 0.347 E+02 & 100.50 & 0.221 E+02 & 120.40 & 0.672 E+01 & 140.30 & 0.137 E+01 \\ 160.20 & 0.207 E+\infty & 180.10 & 0.235 E-01 & 200.00 & 0.197 E-02 & & \end{array}$

WALL MATERIAL PB Of thickness 6.35000 mm and density $11.4000 \quad \mathrm{gm} / \mathrm{cm} * * 3$
at a distance of 1.00000 meters from the scatter point

ENERGY (keV), TRANSUITTED PHOTONS/sec-ov-cm**2-mh-mradh

$\begin{array}{rrrrrrrr}1.00 & 0.000 E+\infty 0 & 20.90 & 0.000 E+\infty & 40.80 & 0.000 E+\infty 0 & 60.70 & 0.834 E-14 \\ 80.60 & 0.196 E-05 & 100.50 & 0.179 E-15 & 120.40 & 0.871 E-10 & 140.30 & 0.520 E-07 \\ 160.20 & 0.960 E-06 & 180.10 & 0.235 E-05 & 200.00 & 0.154 E-05 & & \end{array}$

ABSORPTION MEDIUM

ICRU4

Energy (keV) Surface Dose (rads/sec-ev-milliamp-milliradhoriz) through the wall 1.00000 meters from the scatter point $\begin{array}{llllllll}1.00000 & 0.000000 E+\infty & 20.9000 & 0.000000 E+\infty & 40.8000 & 0.000000 E+\infty & 60.7000 & 0.236113 E-24\end{array}$ $80.6000 \quad 0.623864 E-16 \quad 100.500 \quad 0.707465 E-26 \quad 120.400 \quad 0.426118 E-20 \quad 140.300 \quad 0.308507 E-17$ $160.200 \quad 0.674995 E-16 \quad 180.100 \quad 0.192087 E-15 \quad 200.000 \quad 0.143879 E-15$

All following doses are calculated for $500.000 \mathrm{mill}$ iamps and 5.00000 horizontal milliradians through the wall 1.00000 meters from the scatter point

TOTAL MAXIMUM DOSE 1: $\mathrm{rads} / \mathrm{sec} 2: \operatorname{mrads} / \mathrm{hr} 3: \mathrm{mrads} / \mathrm{yr}$ 


\section{$0.25940 E-07 \quad 0.93319 E-01 \quad 818.04$}

WALL MATERIAL STEEL of thickness $0.000000 E+00 \mathrm{~mm}$ and density $7.80000 \quad \mathrm{gm} / \mathrm{cm} * * 3$ at a distance of 1.00000 meters from the scatter point

ENERGY (keV) , TRANSMITTED PHOTONS/sec-ev-cm**2-mA-mradh

$\begin{array}{rrrrrrrr}1.00 & 0.000 E+\infty & 20.90 & 0.331 E+04 & 40.80 & 0.475 E+04 & 60.70 & 0.219 E+04 \\ 80.60 & 0.609 E+03 & 100.50 & 0.134 E+03 & 120.40 & 0.250 E+02 & 140.30 & 0.391 E+01 \\ 160.20 & 0.505 E+00 & 180.10 & 0.518 E-01 & 200.00 & 0.404 E-02 & & \end{array}$

ABSORPTION MEDIUA

ICRU4

Energy (keV) Surface Dose (rads/sec-ev-milliamp-milliradhoriz) through the wall 1.00000 meters from the scatter point $\begin{array}{lllllllll}1.00000 & 0.000000 E+00 & 20.9000 & 0.448231 E-06 & 40.8000 & 0.179750 E-06 & 60.7000 & 0.619870 E-07\end{array}$ $\begin{array}{llllllllll}80.6000 & 0.193595 E-07 & 100.500 & 0.529513 E-08 & 120.400 & 0.122173 E-08 & 140.300 & 0.232326 E-09\end{array}$ $160.200 \quad 0.355197 \mathrm{E}-10 \quad 180.100 \quad 0.422996 \mathrm{E}-11 \quad 200.000 \quad 0.376374 \mathrm{E}-12$

All following doses are calculated for $500.000 \mathrm{mill}$ iamps and 5.00000 horizontal milliradians through the wall 1.00000 meters from the scatter point

TOTAL MAXIMUA DOSE 1: rads/sec 2: $\mathrm{mrads} / \mathrm{hr} 3: \mathrm{mrads} / \mathrm{yr}$ 40.724 $0.14651 E+090.12843 E+13$

CALCULATION FOR ALL FILTERS COMPLETED 
Listing of the MAPPER plot file: EXAMPLE.PLT and

Plotting EXAMPLE.PLT using MAPPER

Shortened Listing of EXAMPLE.PLT

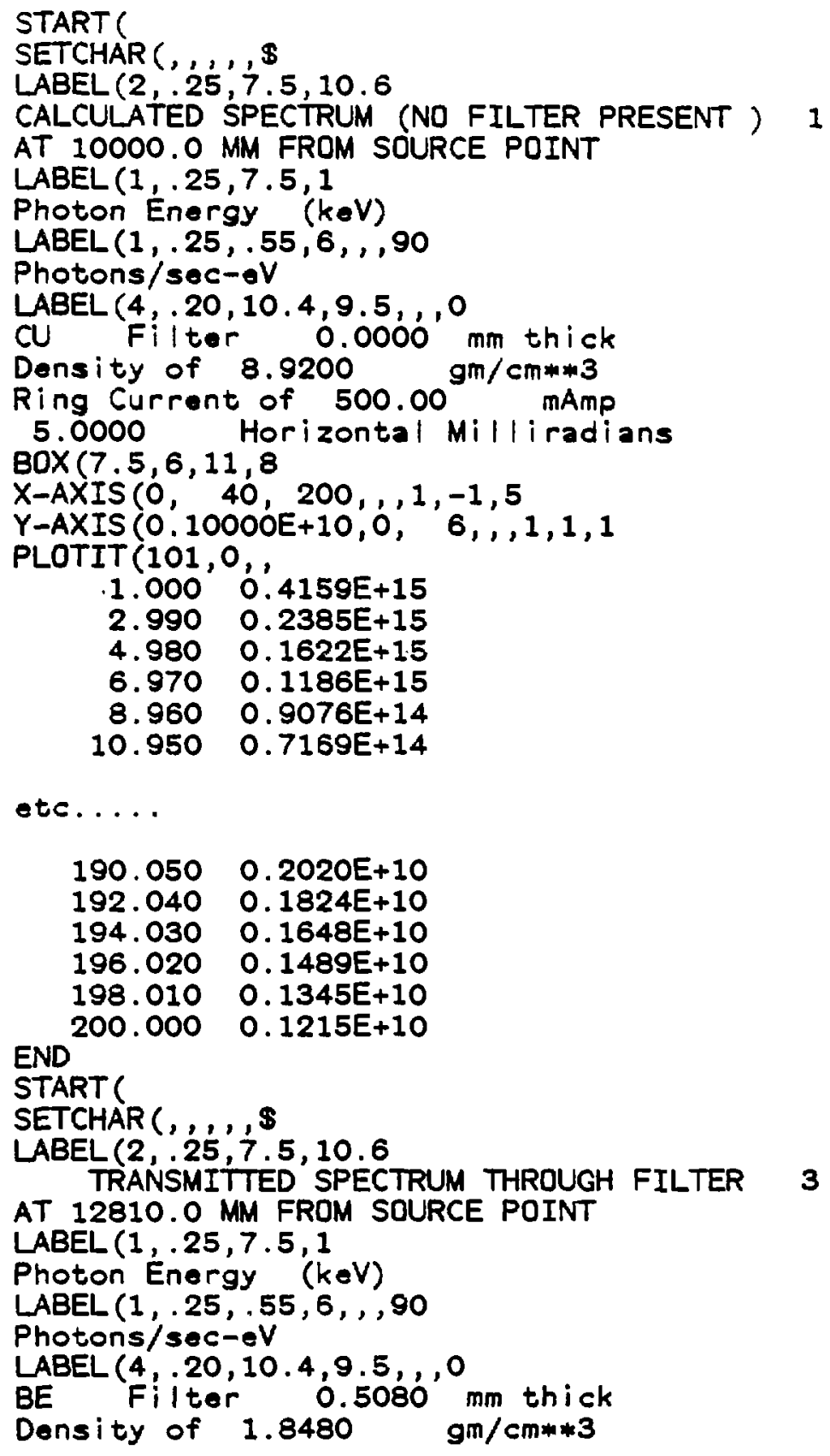


Ring Current of 500.00 mAmp

5.0000 Horizontal Milliradians

$\operatorname{BOX}(7.5,6,11,8$

$X$-AXIS $(0,40,200,,, 1,-1,5$

Y-AXIS $(0.10000 E+09,0,6,1,1,1,1$

PLOTIT (101,0, ,
1.000
$0.1000 E+09$
2.990
$0.2020 E+11$
4.980
$0.2264 E+14$
6.970
$0.5834 E+14$
8.960
$0.6463 E+14$
10.950
$0.5897 E+14$

etc.....

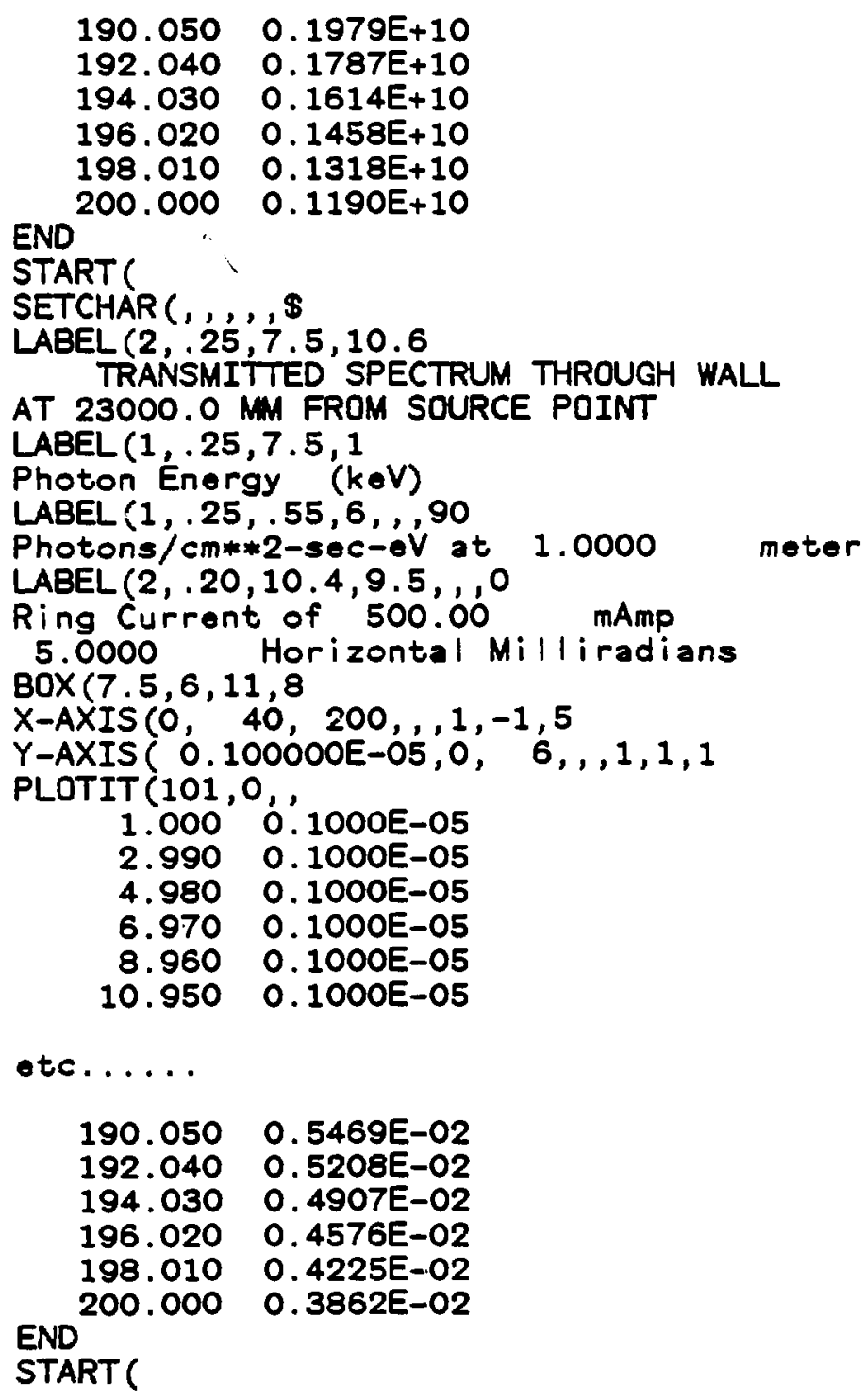




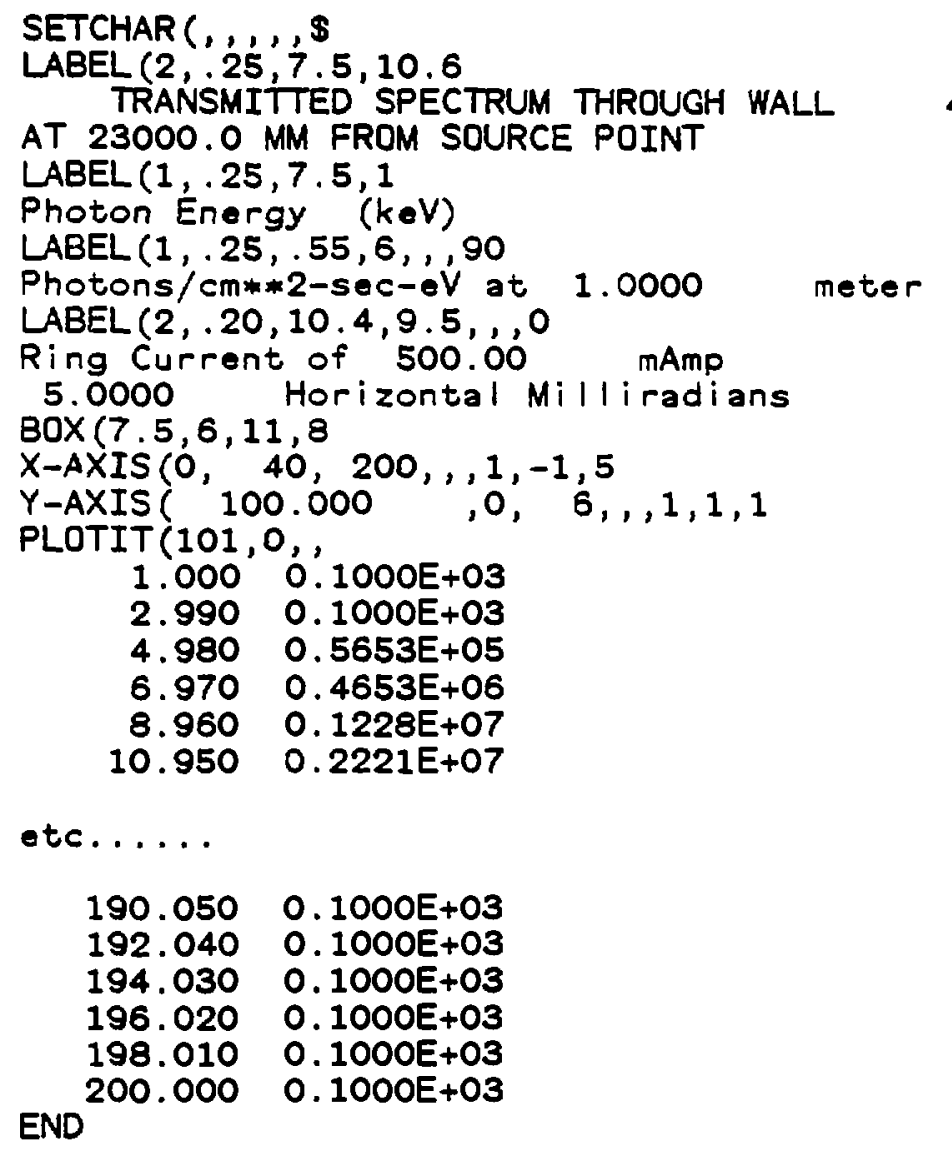

Plotting EXAMPLE.PLT using MAPPER

This file can be plotted by executing the MAPPER program. This is done by typing the following commands:

PROMPT mapper $i=e x a m p l e . p \mid t\langle c r\rangle$

PLOT DEVICE = tek, $4014,2\langle c r\rangle$

If the terminal you are using can emulate a TEKTRONIX 4014, then the following plots will be generated: 


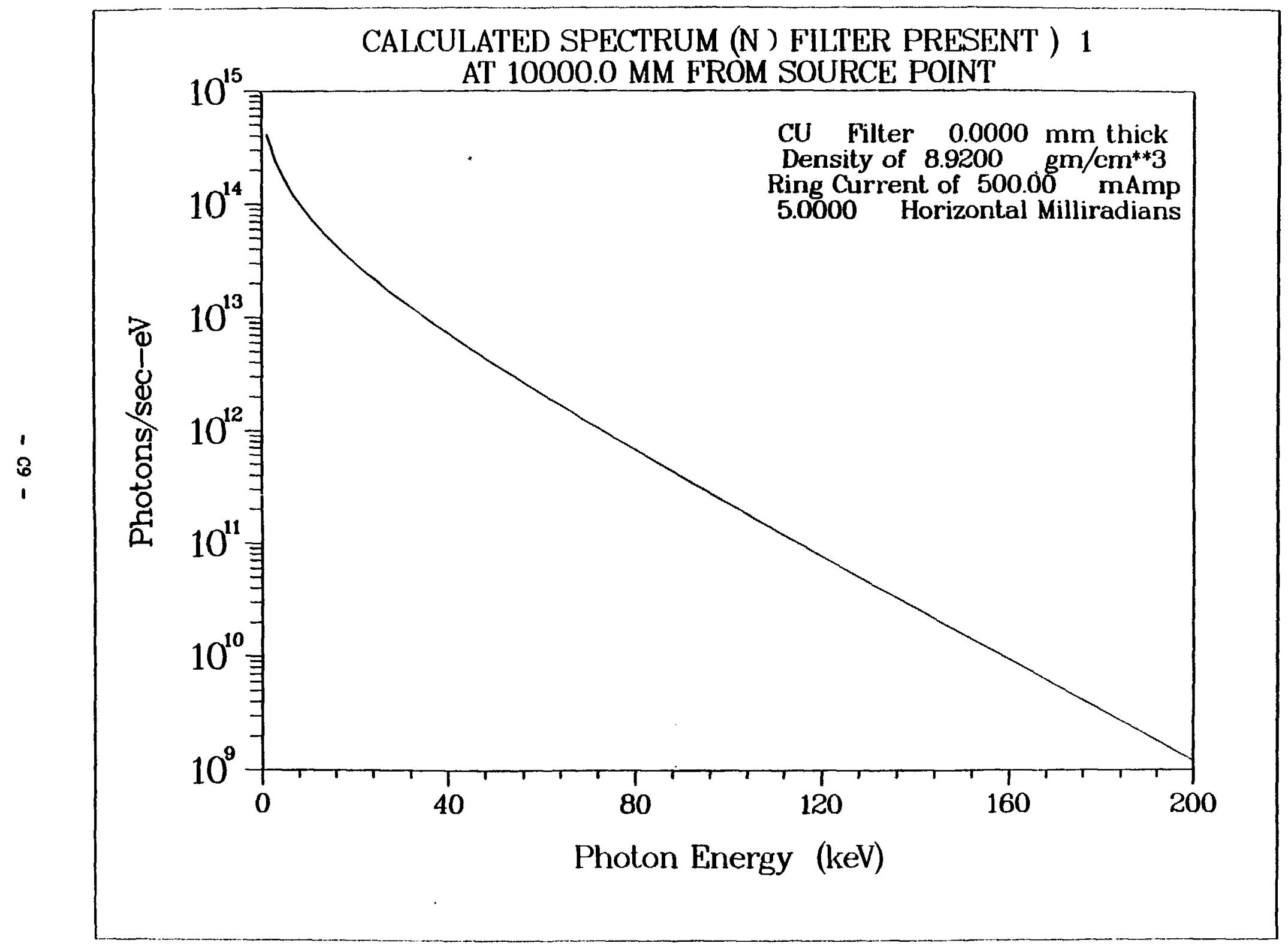




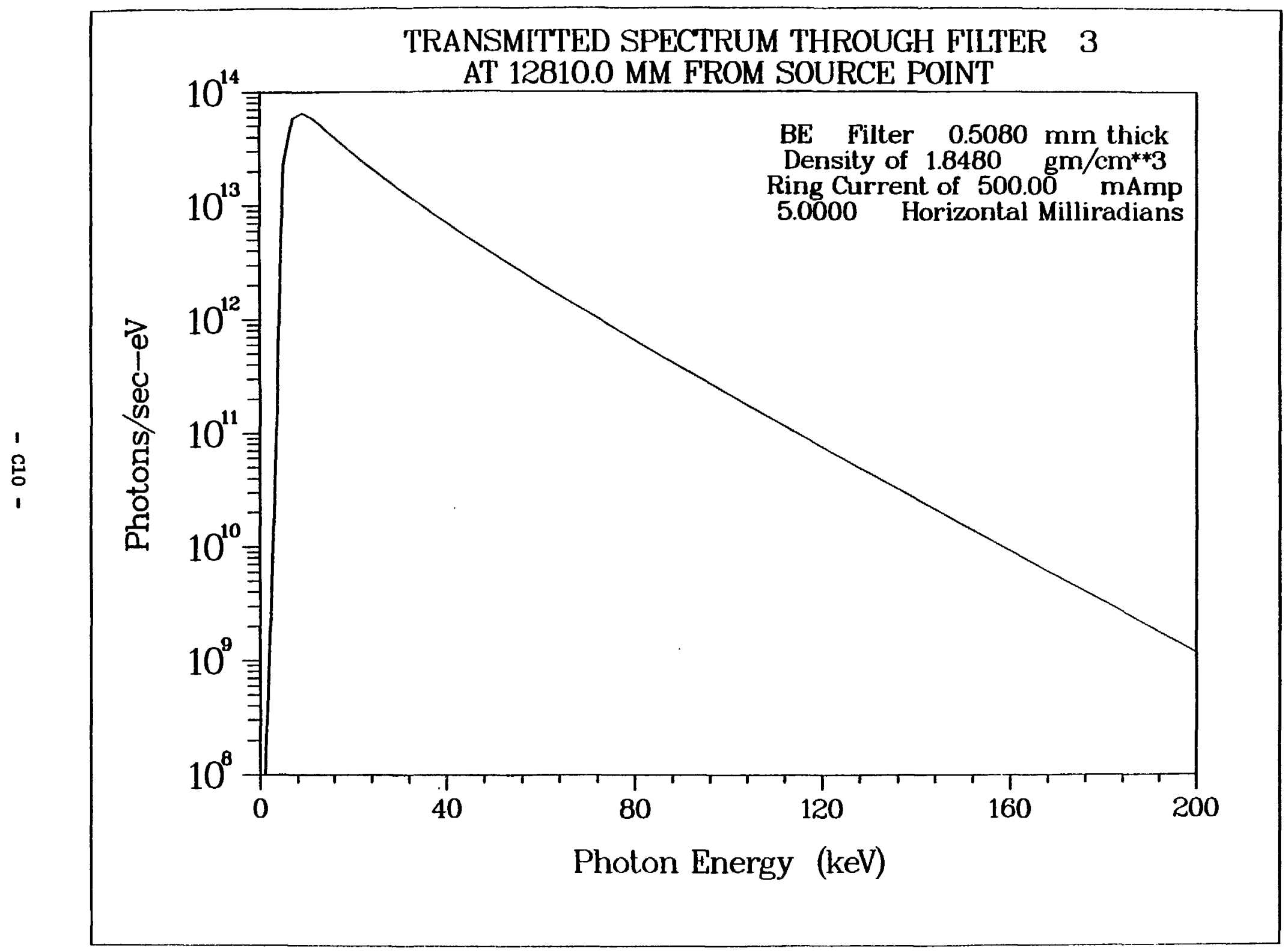




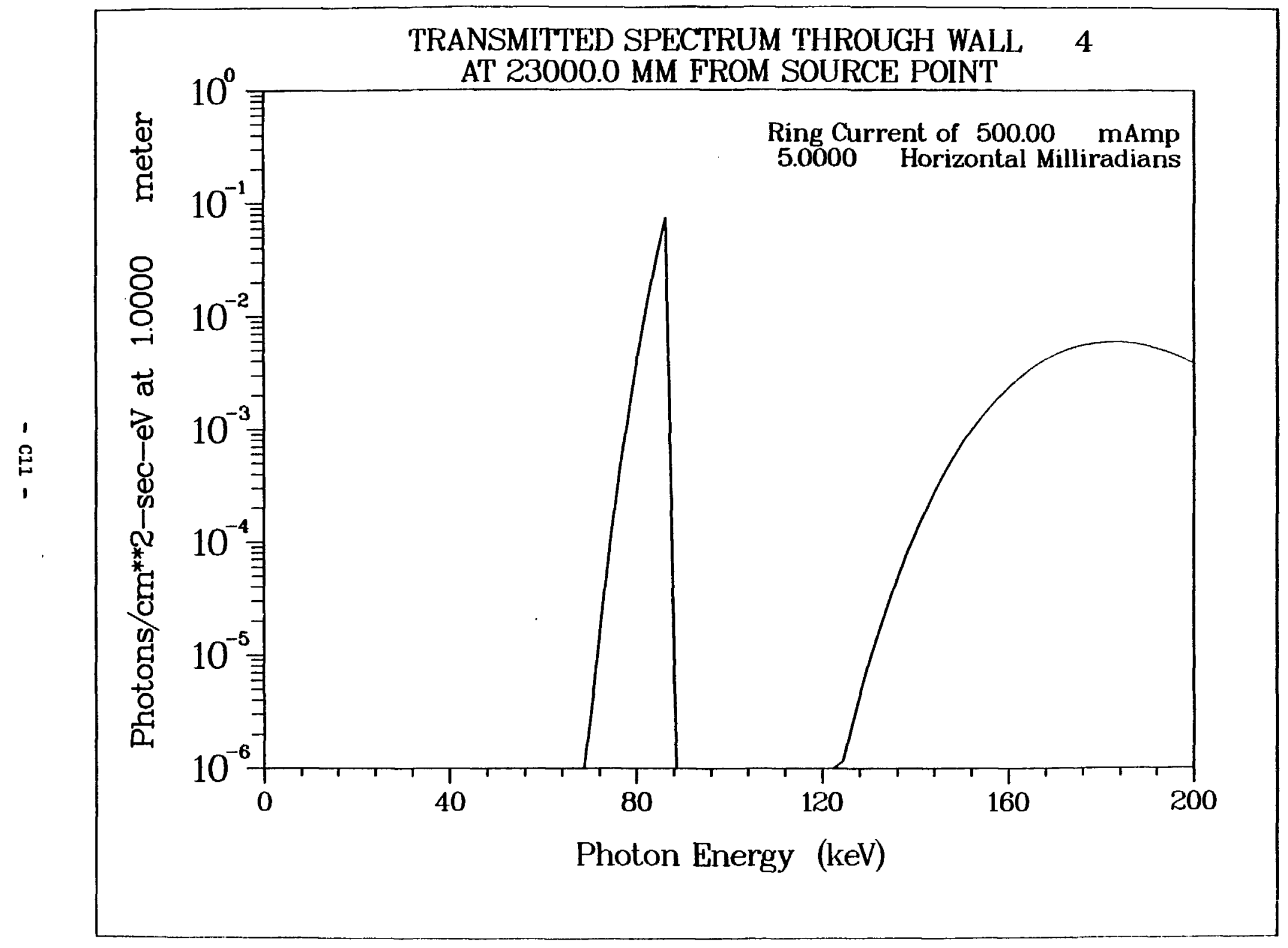




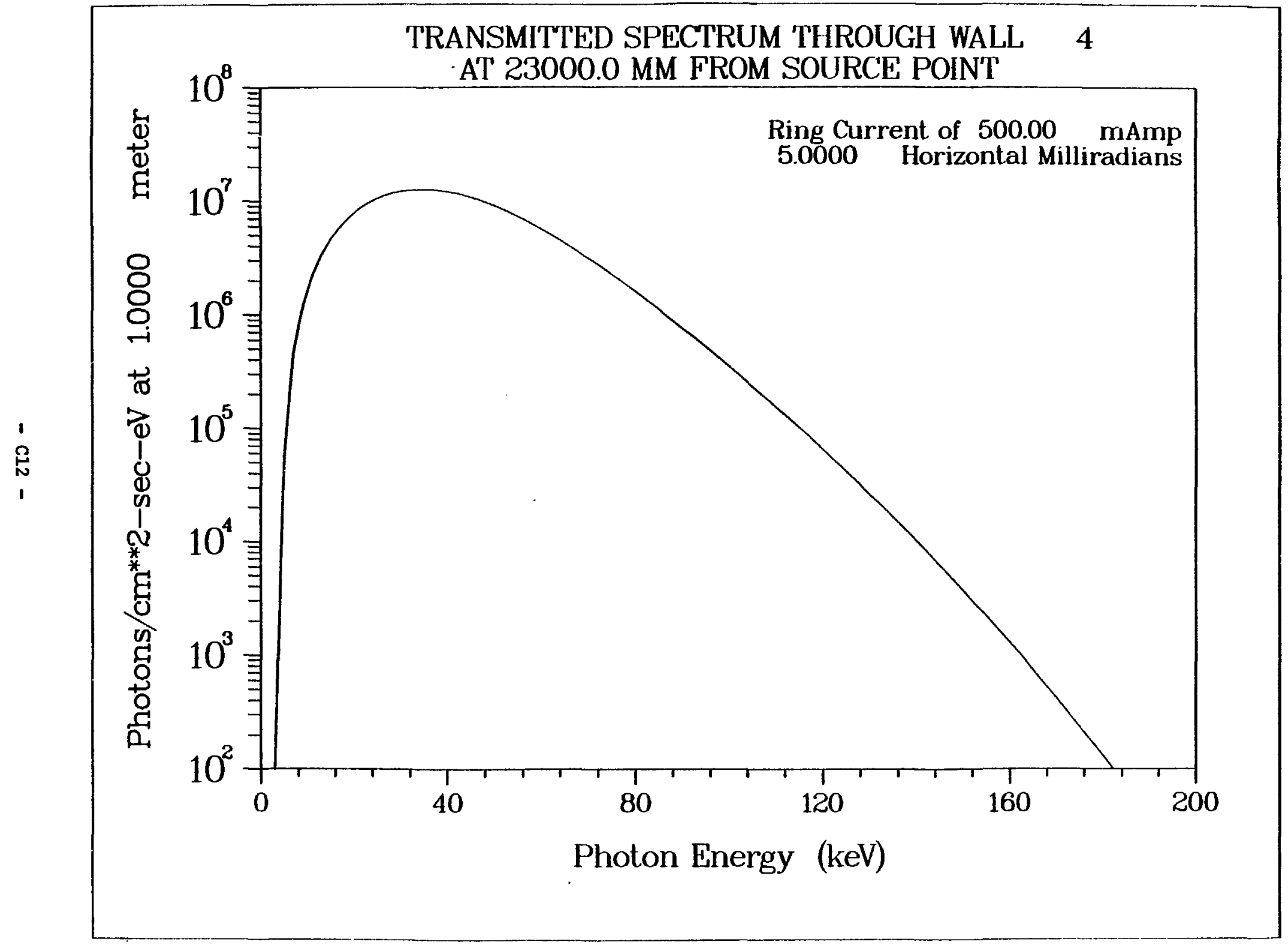

